\title{
Spatiotemporal Regulation of Vibrio Exotoxins by HlyU and Other Transcriptional Regulators
}

\author{
Byoung Sik Kim
}

Department of Food Science and Engineering, ELTEC College of Engineering, Ewha Womans University, Seoul 03760, Korea; b.kim@ewha.ac.kr

Received: 8 August 2020; Accepted: 19 August 2020; Published: 22 August 2020

\begin{abstract}
After invading a host, bacterial pathogens secrete diverse protein toxins to disrupt host defense systems. To ensure successful infection, however, pathogens must precisely regulate the expression of those exotoxins because uncontrolled toxin production squanders energy. Furthermore, inappropriate toxin secretion can trigger host immune responses that are detrimental to the invading pathogens. Therefore, bacterial pathogens use diverse transcriptional regulators to accurately regulate multiple exotoxin genes based on spatiotemporal conditions. This review covers three major exotoxins in pathogenic Vibrio species and their transcriptional regulation systems. When Vibrio encounters a host, genes encoding cytolysin/hemolysin, multifunctional-autoprocessing repeats-in-toxin (MARTX) toxin, and secreted phospholipases are coordinately regulated by the transcriptional regulator HlyU. At the same time, however, they are distinctly controlled by a variety of other transcriptional regulators. How this coordinated but distinct regulation of exotoxins makes Vibrio species successful pathogens? In addition, anti-virulence strategies that target the coordinating master regulator $\mathrm{HlyU}$ and related future research directions are discussed.
\end{abstract}

Keywords: exotoxin; transcriptional regulation; hemolysin; cytolysin; MARTX toxin; secreted phospholipase; HlyU; Vibrio species

Key Contribution: During infection, major exotoxin genes in pathogenic Vibrio species are coordinately but distinctly regulated by $\mathrm{HlyU}$ and other transcriptional regulators for spatiotemporal expression.

\section{Introduction}

The genus Vibrio is composed of various bacterial species that are metabolically versatile. They are commonly found in a wide range of marine environments [1,2]. Although some live as commensals or symbionts in crustaceans, shellfish, squid, or fish, several pathogenic species cause infectious diseases in marine animals. For instance, Vibrio harveyi causes luminescent vibriosis in shrimp, V. alginolyticus causes canker in croakers, $V$. vulnificus causes hemorrhagic disease in aquaculture eels, $V$. crassostreae causes hemocyte lysis in oysters, and V. anguillarum causes erythema and necrotic lesions in Pacific and Atlantic salmon [3-8].

More important, certain Vibrio species are human pathogens that cause various diseases in immune-compromised individuals [9]. People who consume raw or undercooked seafood can get infected by Vibrio species via the intestinal tract. Another route for Vibrio infection is an open wound submersed in contaminated seawater. Depending on the invading species and the health status of patients, symptoms can range from abdominal pain or diarrhea to bacteremia, sepsis, or even death. Well-known examples of human-infecting Vibrio species include V. cholerae, V. vulnificus, $V$. parahaemolyticus, and V. alginolyticus [9]. 
Vibrio species cause disease in humans and animals by producing diverse virulence factors. Some virulence factors promote the proliferation of invading Vibrio in the host and protect them from the host defense systems. For example, V. cholerae expresses a toxin-coregulated pilus that enables the pathogens to aggregate and adhere to gut epithelial cells, facilitating microcolony formation for initial colonization [10-12]. V. vulnificus has evolved many iron scavenging systems and shows extraordinarily rapid growth in high iron sera [13]. Indeed, multiple genes encoding biosynthetic enzymes, transporters, and utilization components for siderophores have been characterized as important virulence genes in this pathogen [14-17]. Capsular polysaccharide is another essential virulence factor for V. vulnificus because the encapsulated strain can resist macrophage-mediated phagocytosis $[18,19]$. The ability to use host-specific carbohydrates is another crucial trait for pathogens because invading bacteria compete with the host and residual commensals for nutrients [20]. Consistent with this, Vibrio mutants that are unable to use sialic acids, a distal end carbohydrate found in host mucins, showed colonization defects in mouse infection experiments [21,22]. Reduced virulence was also observed in V. vulnificus when a specific transcriptional regulator for the sialic acid utilization system was mutated [23,24]. This latter result emphasizes that virulence factors must be accurately regulated at the transcription level to enable successful pathogenesis.

Another kind of virulence factor in bacterial pathogens is secreted protein toxins, or exotoxins. Unlike the above-mentioned virulence factors, exotoxins are inherently destructive and affect the integrity of host cells and tissues through their enzymatic functions $[25,26]$. In pathogenic Vibrio species, especially $V$. cholerae, V. vulnificus, and V. anguillarum, the following exotoxins and their transcriptional regulation mechanisms have been substantially characterized: cytolysin/hemolysin, multifunctional-autoprocessing repeats-in-toxin (MARTX) toxin, secreted phospholipase, and vibriolysins (Figure 1a-d) [27-39]. Because the inactivation of any of these toxins in $V$. vulnificus significantly compromises its virulence [36,40-42], it is speculated that homologous exotoxins in other pathogenic Vibrio species could contribute to their virulence and disease progression. Notably, the transcriptional regulator HlyU has been found to bind to the regulatory region of all these exotoxin genes and control their expression, except for the vibriolysin genes $[32,33,35,36,43]$. Diverse transcriptional regulators other than HlyU also control exotoxin expression by conveying environmental cues.

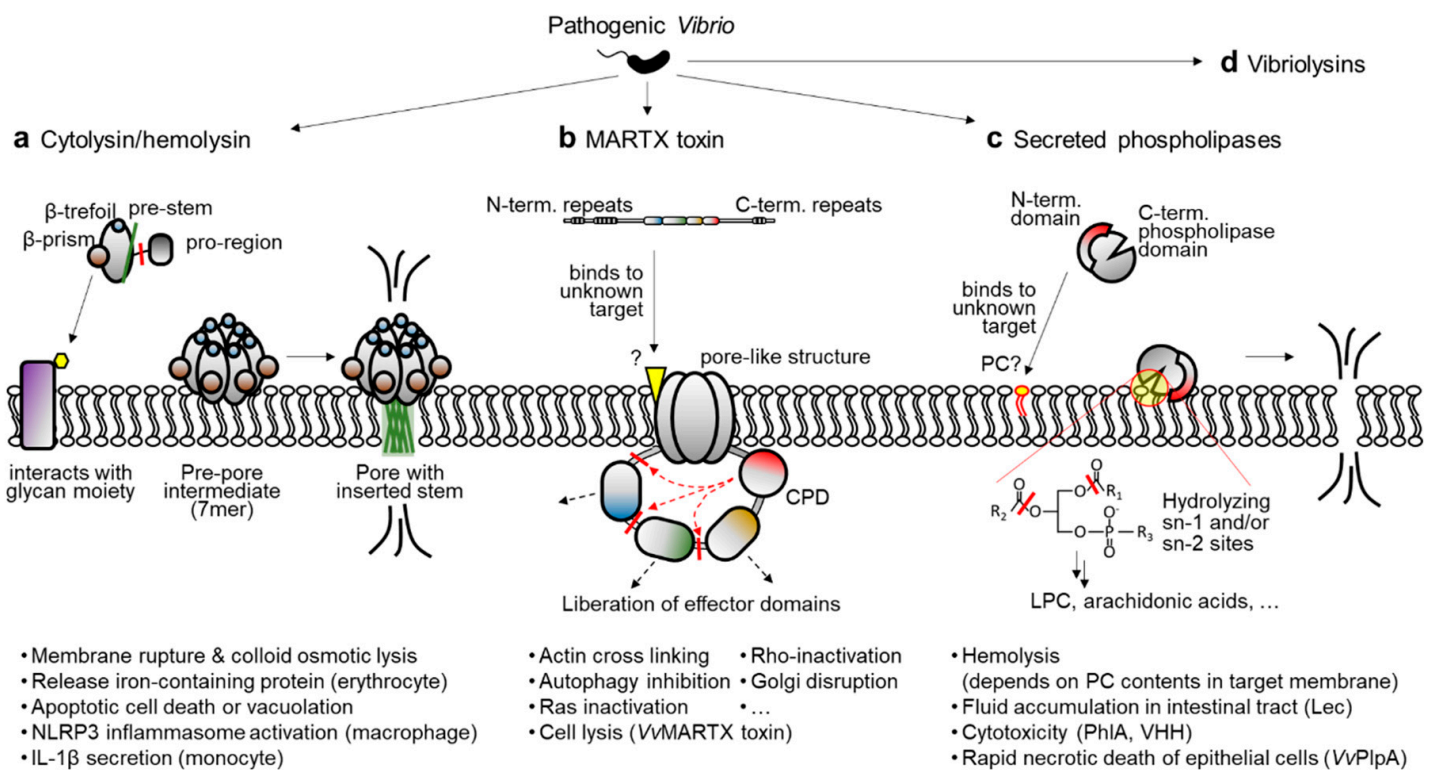

Figure 1. Major exotoxins produced by pathogenic Vibrio species. (a) After secretion from the bacterium, cytolysin/hemolysin is activated by processing of the pro-region. The resulting active toxin then binds to the target cell membrane, and seven monomers are assembled to form a pre-pore intermediate. During this assembly, pre-stems are extended, tightly gathered, and inserted into the membrane, establishing a 
$\beta$-barrel pore. (b) Multifunctional-autoprocessing repeats-in-toxin (MARTX) toxin secreted via atypical T1SS binds to the host cell membrane, probably by interacting with yet unidentified target molecule(s). Amino- and carboxyl-terminal repeat-containing regions of the toxin form a pore-like structure on the membrane. Central effector domains are then translocated into the host cell through that pore. In the cytosol, the cysteine protease domain (CPD) processes and liberates the cytopathic effectors. (c) Phospholipase is secreted from the bacterium via T2SS. At the target cell membrane, the toxin hydrolyzes the sn- 1 and sn-2 sites of phospholipid substrates, producing diverse signaling molecules such as lysophosphatidylcholine (LPC). Because the toxin exhibits hemolysis activity that depends on the phosphatidylcholine (PC) content, it is speculated that the amino-terminal domain of the toxin interacts with PC on the membrane. (d) Proteolytic exotoxins termed vibriolysins are also produced by pathogenic Vibrio species. For recent reviews see [44-46]. The consequences of each exotoxin are summarized at the bottom of the figure. VvMARTX toxin, V. vulnificus MARTX toxin; Lec, V. cholerae lecithinase; PhlA, V. mimicus phospholipase A; VHH, V. harveyi hemolysin; VvPlpA, V. vulnificus phospholipase A.

It should be noted here that the details of function, pathogenic property, and transcriptional regulation mechanism of the vibriolysins have already been reviewed in other recent articles [44-46]. Therefore, this review will focus only on the HlyU-regulated Vibrio exotoxins. Accordingly, following sections summarize the functional characteristics of the three remaining Vibrio exotoxins, along with their regulation mechanisms governed by HlyU and other transcriptional regulators. In addition, recent attempts to develop an anti-virulence strategy by targeting HlyU will be discussed, and suggestions for future research directions will be made.

\section{Major Exotoxins Produced by Pathogenic Vibrio Species}

\subsection{Cytolysin/Hemolysin}

Among the various exotoxins produced by pathogenic Vibrio species, hemolysin has been studied extensively because it is widely distributed in vibrios and exhibits prominent outcomes as a potent exotoxin $[47,48]$. Hemolysin lyses the membrane of erythrocytes and releases iron-containing proteins such as hemoglobin. This is important for pathogenic Vibrio species because iron is a critical metal for bacterial cell proliferation, especially in a host where readily available free iron is quite limited $[49,50]$. Accordingly, hemolysin is considered to be a crucial virulence factor of pathogenic vibrios.

Mainly two hemolysin families are present in Vibrio species [48]. One is the thermostable direct hemolysin (TDH) family, originally characterized in $V$. parahaemolyticus [51,52]. As suggested by its name, this hemolysin can withstand high temperature, and thus heating at $100{ }^{\circ} \mathrm{C}$ is not enough for toxin inactivation. The $\beta$-hemolysis activity of this TDH toxin has been linked to clinical isolates of $V$. parahaemolyticus. The THD-related hemolysins (TRHs) also exist in some $V$. parahaemolyticus strains [53]. Unlike the TDHs, however, TRHs are heat-labile and easily inactivated by heat.

The other hemolysin family in Vibrio species is the El Tor hemolysin (HlyA) family, originally isolated in $V$. cholerae [48,54]. Many cell types other than erythrocytes have been reported to be affected by the HlyA family hemolysins. For instance, hemolysin from $V$. cholerae can induce apoptotic cell death in intestinal epithelial cells [55]. Furthermore, fluid accumulation and intestinal tissue damage have been linked to this family of toxins in $V$. cholerae-inoculated rabbit ileal loops and V. vulnificus-infected mice $[40,55]$. Therefore, HlyA family hemolysins in pathogenic Vibrio species are also called cytolysins; in $V$. cholerae, HlyA is the same toxin as V. cholerae cytolysin (VCC) [56]; in V. vulnificus, the same family of cytolysin/hemolysin is called V. vulnificus hemolysin (VVH) [57]; in V. anguillarum, it is called VAH [58]; and in V. mimicus, it is called VMH [59].

These cytolysin/hemolysin executes its function by forming pores in the plasma membrane of the target cells. Indeed, HlyA belongs to the $\beta$-barrel pore-forming toxin family. This family also includes other bacterial hemolysins such as aerolysin from Aeromonas and the $\beta$-toxin of Clostridium [60-62]. 
Notably, cytolysin/hemolysin in vibrios is produced as an inactive precursor containing both a signal peptide sequence and a pro-region at the amino-terminus [63]. The signal peptide is removed during translocation of the toxin from the bacterial cytosol to the periplasm, whereas the pro-region is processed by multiple proteases after the inactive pro-toxin is secreted extracellularly [64,65]. It should be noted that, unlike VCC or VMH, VVH has no pro-region [31,57]. Instead, the VVH-encoding vvhA gene is co-expressed with its upstream gene $v v h B$, which encodes a putative molecular chaperon for $\mathrm{VVH}$ that is similar to the pro-region of VCC or VMH [66].

In any case, the processed toxin monomers must be clustered and made into a heptameric state to form a pore in the host cell membrane (Figure 1a). First, the toxin monomer binds to the sugar molecules presented on the membrane, which is mediated by lectin-like domains at the carboxyl-terminal region of the toxin. For instance, recent studies have revealed that a $\beta$-prism domain of VCC tightly interacts with a branched pentasaccharide moiety $\left(\mathrm{GlNNAc}_{2}-\mathrm{Man}_{3}\right)$ typically found in the complex $\mathrm{N}$-glycans of mammalian cell-surface proteins $[67,68]$. After binding to the membrane, monomeric toxins are self-assembled into a heptamer and form a pre-pore intermediate [69]. During this transition, the pre-stem loop of each protomer detaches from the core part of the protein and forms an anti-parallel $\beta$-hairpin stem. The hairpins extracted from seven protomers are then tightly assembled and inserted into the membrane to form a $\beta$-barrel pore (Figure 1a) $[61,69]$.

The consequence of pore formation by cytolysin/hemolysin is not just membrane rupture and the colloid osmotic lysis of target cells. As reviewed by Khilwani and Chattopadhyay, VCC can induce apoptotic cell death signaling and vacuolation in various types of epithelial cells [70]. In case of immune cells, cytolysin/hemolysin can induce inflammatory responses. For example, VCC and VVH activate the NOD-like receptor family pyrin domain-containing 3 (NLRP3) inflammasome in murine macrophages [71]. Similarly, VCC has been shown to cause NLRP3 and ASC (apoptosis-associated speck-like protein-containing a CARD domain)-dependent secretion of interleukin-1 $\beta$ from human THP-1 monocytes [72]. In combination with the lysis of iron-containing erythrocytes, these pro-inflammatory consequences of cytolysin/hemolysin emphasize the importance of its precise regulation in pathogenic Vibrio species.

\subsection{MARTX Toxin}

A study aiming to identify the reasons for the remaining reactogenicity in live attenuated $V$. cholerae vaccine strains identified a gene cluster that corresponds with cytotoxic activity toward Hep-2 cells [73]. A sequence analysis revealed that the gene cluster is physically linked to the cholera toxin (CTX) prophage genes in chromosome, but it encodes components of the RTX (repeats in toxin) family toxin system: RTX toxin, toxin activator, and toxin secretion proteins [73]. Similar to other RTX family toxins in pathogenic bacteria, $V$. cholerae RTX toxin has glycine/aspartic acid (GD)-rich repeats and a secretion signal peptide sequence at the carboxyl-terminal region. However, unlike the prominent RTX toxin from pathogenic Escherichia coli, the V. cholerae RTX did not show any apparent hemolytic activity. Instead, other cytopathic activities, such as actin-cross linking activity and Rho protein-inactivation, were observed. These activities have been linked to two distinct domains of the toxin [74-76].

Later, other putative cytotoxic/cytopathic effector domains were further found in this $V$. cholerae RTX toxin and its homologous toxins in other pathogenic bacteria $[77,78]$. Notably, a cysteine protease domain (CPD) responsible for the effector domain processing is also present in the toxins $[77,79]$. Because cytotoxic/cytopathic effector domains are delivered into the host cells along with the CPD, and the CPD is activated by the host specific molecule inositol hexakisphosphate, the effector domains are thought to be liberated from the holo-RTX toxin in the host cells (Figure 1b) $[77,80]$. To acknowledge the structural and functional features of the $V$. cholerae RTX toxin and its homologs, this specific toxin family has been renamed the MARTX (multifunctional autoprocessing RTX) toxin [77].

Early characterizations of the MARTX toxin were mainly conducted using $V$. cholerae El Tor strain N16961, and thus the toxin was considered as an accessory toxin behind the highly potent CTX $[73,74,81]$. However, multiple independent studies conducted with other pathogenic Vibrio 
species, such as $V$. vulnificus and $V$. anguillarum, revealed that the MARTX toxin is essential for the pathogen's cytotoxicity in vitro and pathogenicity in vivo [41,42,82-84]. Indeed, unlike the V. cholerae MARTX toxin, which has never shown hemolytic or cytolytic activity [73,74], a MARTX toxin from $V$. vulnificus exhibited rapid cytolytic activity by forming pore-like structures with an estimated radius of $1.63 \mathrm{~nm}$ on the target cell membrane. Consequently, the intoxicated host cells released their cytosolic contents, including lactate dehydrogenase, into culture supernatants [41,42,82]. Recently, the cytolytic activity of the $V$. vulnificus MARTX toxin has been linked to the repeats-containing regions at its aminoand carboxyl-terminal arms [85]. Consistent with its absence of cytolytic activity, the same regions of the $V$. cholerae MARTX toxin did not lyse the host cells [86].

Not only the actin-cross linking domain and Rho-inactivation domain but also many other cytopathic domains have been identified in Vibrio MARTX toxins (Figure 2) [78,80]. For instance, autophagy and endosomal trafficking of infected cells were inhibited by an alpha/beta hydrolase domain $(\mathrm{ABH})$ of the $V$. cholerae MARTX toxin [87]. Prohibitin-1 was identified as an interacting partner of the domain of unknown function at the first position (DUF1) of the V. vulnificus MARTX toxin and suggested to serve as a receptor for the toxin [88]. The integrity of Golgi was affected by both the makes caterpillars floppy-like and domain X domains (MCF and DmX) [89-91], and Ras-ERK signaling was disrupted by the Ras/Rap1-specific endopeptidase domain (RRSP) of the V. vulnificus MARTX toxin [92-94]. In addition, cyclic AMPs were massively produced in intoxicated cells by an actin-stimulated ExoY-like domain $[95,96]$.

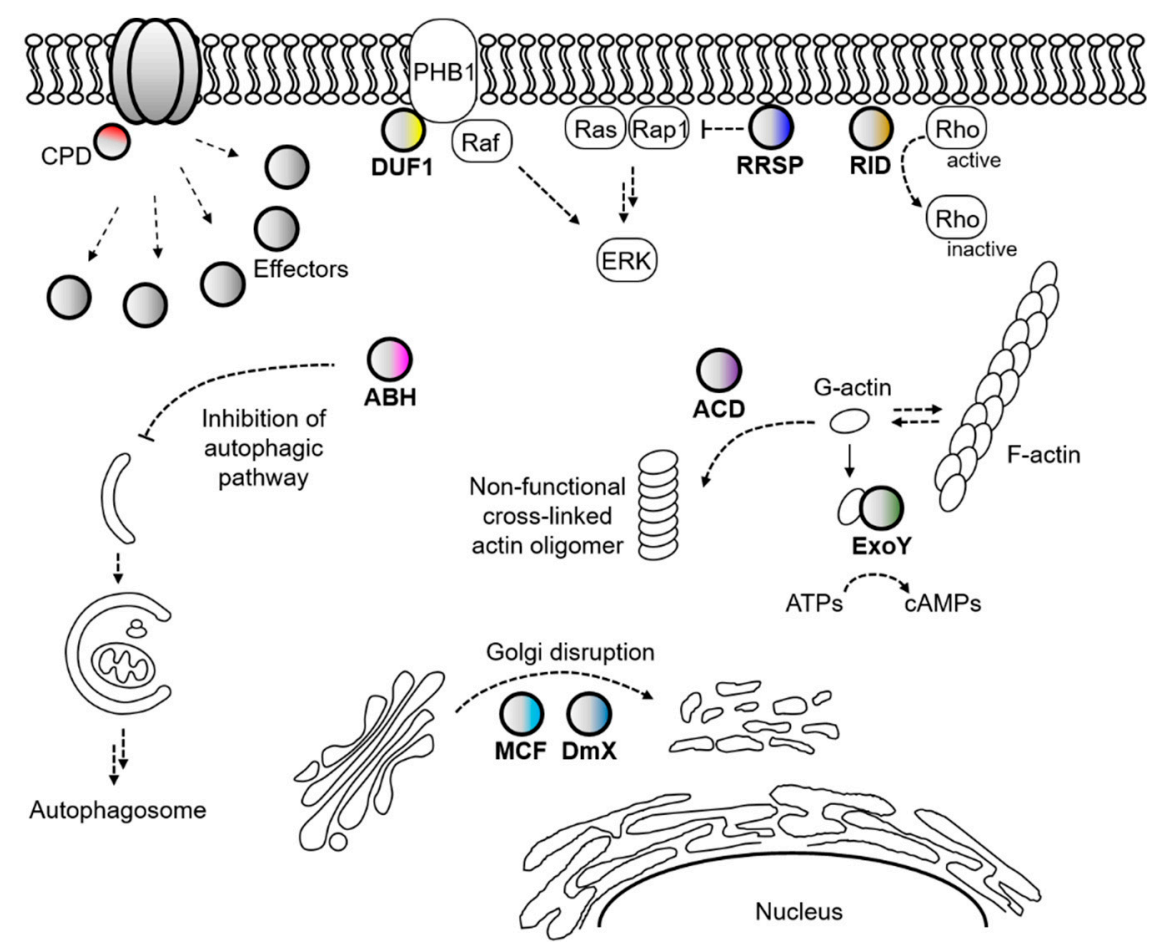

Figure 2. MARTX toxin effector domains and their effects on host cell targets. After release from the holo-MARTX toxin, effector domains interact with their target proteins or molecules in the host cell cytosol, exhibiting cytopathic consequences. PHB1, prohibitin-1; G-actin, monomeric globular actin; F-actin, fibrous actin.

Because varying numbers and combinations of these cytopathic effector domains are present in each different MARTX toxin, and they are delivered by the toxin itself, the MARTX toxin is somewhat similar to the type 3 secretion system (T3SS) or T4SS of bacterial pathogens [78,97]. However, the consequence of MARTX intoxication is more complicated because MARTX effectors are delivered into the target cell all at once [98,99]. Nonetheless, the MARTX effectors can be relatively easily 
coordinated with other virulence factors at the transcriptional level than the T3S or T4S effector proteins. This is because the MARTX effectors are residing in a single protein, the MARTX toxin, as modular domains.

\subsection{Secreted Phospholipases}

Phospholipases are lipolytic enzymes that hydrolyze ester or phosphoester linkages in phospholipids. Because the cell membranes of eukaryotes are mainly composed of phospholipid bilayers, phospholipases secreted by pathogens often act as virulence factors by affecting the integrity of the cell membrane. In addition, some phospholipases can elicit or dysregulate cell signaling pathways involved in apoptosis or inflammation because they eventually produce diverse signaling molecules such as arachidonic acid and lysophosphatidylcholine (LPC) [100,101]. For example, Clostridium perfringens produces cytotoxic phospholipase $\mathrm{C}$, which causes chloride secretion from rat colons [102], and Pseudomonas aeruginosa produces and translocates the T3S effector ExoU, a patatin-like phospholipase $\mathrm{A}_{2}$ associated with lung injury and sepsis in mice [103].

Many Vibrio species also produce and secrete phospholipases into extracellular milieu [36,104-108]. In early studies, Mizuguchi and colleagues found a thermolabile hemolysin (TLH) gene from $V$. parahaemolyticus $[109,110]$. Later, the same group revealed that the TLH is actually a phospholipase with phospholipase A and lysophospholipase activity [111]. Since then, independent groups have reported several homologous proteins from various Vibrio species. Based on sequence homology, the TLH family of phospholipases includes the TLH of $V$. parahaemolyticus, Lec (lecithinase) of $V$. cholerae, PhlA (phospholipase A) of V. mimicus, VHH (V. harveyi hemolysin) of V. harveyi, VaPlpA (V. anguillarum phospholipase A) of $V$. anguillarum, and $V v P l p A$ (V. vulnificus phospholipase A) of V. vulnificus [112]. It should be noted that all these proteins contain a putative signal peptide sequence for T2SS at the amino-terminus, and VvPlpA has actually been found to be secreted via that system [36,112]. Thus, TLH family phospholipases in vibrios are believed to act as exotoxins after being secreted from the bacterium (Figure 1c).

Despite the substantial level of sequence homology, the biochemical properties of the secreted phospholipases are somewhat distinct from one another. For instance, the TLH of V. parahaemolyticus can hydrolyze both fatty acid esters in phosphatidylcholine (PC) positioned at the sn-1 and sn-2 sites. It can also hydrolyze LPC, producing a free fatty acid and glycerophosphorylcholine [111]. In contrast, the $V$. mimicus PhlA does not possess lysophospholipase activity, even though it cleaves both sn- 1 and sn-2 sites like TLH [106]. No lysophospholipase activity had been detected with V. anguillarum VaPlpA or $V$. vulnificus VvPlpA, but a fatty acid at sn-2 site was preferentially cleaved, indicating that these two enzymes belong to the phospholipase $A_{2}$ family $[36,108]$.

The hemolytic activity and cytotoxicity of the secreted phospholipases and their effects on the overall virulence of Vibrio species are also quite different. PhlA, VHH, and VaPlpA have been shown to have hemolytic activity only against erythrocytes obtained from fish such as rainbow trout, tilapia, or salmon [106-108]. Rabbit, human, and sheep erythrocytes exhibited very little or no lysis upon PhlA or VaPlpA treatment [106,108]. In contrast, VvPlpA showed substantial levels of hemolytic activity on human and horse erythrocytes but not on sheep erythrocytes [36]. These results suggest that each phospholipase could require a different PC level in the target membrane to lyse it because the PC content of the total erythrocyte phospholipids in fish, rabbits, humans, and sheep are quite different each other (about 58\%, 34\%, 17\%, and 4\%, respectively) [106,113].

The in vivo potencies of the secreted phospholipases also differ widely. The culture supernatant of wildtype (WT) V. cholerae, but not the Lec mutant strain, caused human intestinal cell (HT29/C1) loss. However, in ligated rabbit ileal loop infection experiments, the Lec mutant showed a level of fluid accumulation comparable with that from the WT strain, indicating that the phospholipase activity of Lec is not a major factor responsible for fluid accumulation [105]. PhlA and VHH exhibited significant cytotoxicity in CHSE-214 fish cells and flounder gill cells, respectively [106,107]. But only the VHH preparation induced flounder death after intraperitoneal (i.p.) infection [107]. The most 
profound difference was observed between $V a P l p A$ and $V v P l p A$. Although the V. anguillarum mutant defective for $\mathrm{VaPlpA}$ showed a two- to three-fold decrease in hemolytic activity on fish blood agar, its virulence did not differ statistically from that of the WT strain in fish infection experiments [108,114]. In contrast, the $V$. vulnificus mutant defective for $V v$ PlpA showed significantly attenuated virulence in mice infection experiments, demonstrating that $V v P l p A$ is a crucial virulence factor for this pathogen. $V v$ PlpA also contributed to the rapid necrotic death of human epithelial INT-407 cells [36].

Recently, the three-dimensional crystal structure of VvPlpA was resolved at 1.4- $\AA$ resolution [112]. The protein consists of two close-packed domains, an amino-terminal domain of unknown function, and a carboxyl-terminal phospholipase domain. Although no function has yet been suggested for the amino-terminal domain, it is speculated to play important roles in the TLH family of secreted phospholipases because a central part of the domain, the $\beta 1$ strand, is strictly conserved in all these phospholipases [112]. Because the $V$. parahaemolyticus TLH showed lecithin-dependent hemolytic activity and the other secreted phospholipases exhibited PC-dependency for erythrocyte lysis, it would be useful to determine whether the amino-terminal domain senses a PC molecule on host cell membranes and induces concomitant conformational changes in the carboxyl-terminal active domain. Another noticeable feature discovered by the structural study is that the catalytic site in $V v P l p A$ seems to be degenerated and consists of a Ser-His-Gly triad instead of a Ser-His-Asp/Glu triad. A chloride ion sitting at the catalytic site, however, functions as a substitute for the acidic Asp/Glu residue. Among the various TLH family of secreted phospholipases in Vibrio species, only VvPlpA and VaPlpA, which show phospholipase $\mathrm{A}_{2}$ activity, have a Gly, not an Asp or Glu, at the third position of the catalytic triad. Therefore, it would also be intriguing to test whether this variation in the catalytic triad is related to the specific activity of the TLH family of secreted phospholipases.

\section{Coordinated but Distinct Regulation of Exotoxin Genes in Vibrio Species}

To determine the factor regulating the $V$. cholerae hemolysin/cytolysin gene $h l y A$, Williams and Manning screened a genomic library of the V. cholerae O17 strain in E. coli along with an hlyA-cat fusion reporter plasmid [115]. By characterizing the genomic library region of clones that showed increased chloramphenicol acetyl transferase (cat) activity, they first discovered a $h l y U$ gene and characterized its product, $\mathrm{HlyU}$, as an activator of the hlyA $[115,116]$. More than a decade later, a homologous protein in $V$. vulnificus was found to positively regulate both the $r t x A$ and $p l p A$ genes, which encode the MARTX toxin and secreted phospholipase $A_{2}$, respectively $[36,42]$. Similarly, HlyU in $V$. anguillarum has been found to regulate the expression of the vah1-plp and $r t x A C H-B D E$ clusters encoding cytolysin/hemolysin, secreted phospholipase, and MARTX toxin system [117]. The detailed mechanisms of this HlyU-mediated transcriptional regulation of major Vibrio exotoxins will be summarized and compared in the following sections after a short review of the HlyU protein itself.

\subsection{HlyU, a Common Transcriptional Regulator of Major Exotoxin Genes in Vibrio Species}

$\mathrm{HlyU}$ is a small, homo-dimeric transcriptional regulator widely distributed in many Vibrio species. Structural analyses of $V$. vulnificus and V. cholerae HlyUs revealed that the protein belongs to the ArsR/SmtB family of transcriptional regulators $[118,119]$. Like other members of this family, HlyU harbors a winged helix-turn-helix (wHTH) motif predicted to interact with the target DNA molecule. Generally, a recognition helix in the wHTH motif is inserted into a major groove, whereas the winged region composed of short antiparallel $\beta$-strands is inserted into a minor groove of the DNA [120]. Although the complex structure of DNA-bound HlyU is not yet available, that DNA binding mode has been repeatedly proposed by independent groups conducting structural modeling study $[118,119,121]$. All those binding models suggest that the DNA bends upon HlyU binding because the distance between the two recognition helices in the dimeric form of HlyU is shorter than $34 \AA$, the distance between two consecutive major grooves in B-DNA.

A feature that distinguishes HlyU from other ArsR/SmtB family proteins is that it does not bind to metal ions $[118,119,122]$. ArsR, a profound example of this family of transcription factors, directly 
senses heavy metal arsenate using a highly conserved cysteine residue in the so-called "metal binding box." This binding induces conformational changes in ArsR that lead to protein dissociation from the operator DNA molecule [123]. Interestingly, the "ELCV $(C / G) D$ " motif of the metal binding box is degenerated and replaced with "ELSVGE" in the Vibrio HlyU proteins. Moreover, other metal binding residues in the second metal binding site in the dimeric interface of ArsR/SmtB family proteins are also replaced by non-metal binding residues in the Vibrio HlyUs [121]. Therefore, it appears that HlyU is not a metal-sensing transcriptional regulator [118,119].

Instead, Chakrabarti and colleagues proposed that HlyU might sense oxygen levels in its local environment and regulate its regulon as a redox switch [119,122]. Indeed, one of two sole cysteine residues in the $V$. cholerae HlyU was modified by sulfenic acid in a crystal structure, whereas that oxidation was absent if the structure was solved under reducing conditions [119]. Molecular dynamic simulations further suggest that the predicted sensing role of the cysteine residues could be linked to DNA binding activity because the distance between the oxidizing cysteine and another cysteine residue exhibited a strong correlation with the DNA binding status [122]. Although more direct evidence should be collected, this model is of great interest because pathogenic Vibrio species face microaerobic or anaerobic conditions when they invade the host intestinal tract [124].

\subsection{Transcriptional Regulation of Cytolysin/Hemolysin Genes in Vibrio Species}

Consistent with the role of hemolysin in releasing iron-containing proteins from erythrocytes, hemolysin synthesis was found to be iron-regulated in V. cholerae [125]. Furthermore, the introduction of the E. coli fur gene into the $V$. cholerae mutant strain that constitutively produces hemolysin reestablished the iron-dependent regulation of hemolysin synthesis. These results suggest that the transcription factor Fur, with iron as a corepressor, represses the cytolysin/hemolysin gene hlyA in $V$. cholerae, just as it does in E. coli [125]. HlyU was also found to positively regulate the transcription of $h l y A$ [116]. Tsou and Zhu discovered that a quorum sensing master regulator, HapR, directly represses $h l y A$ expression [28].

Recently, precise binding sites were determined for Fur, HlyU, and HapR in the hlyA promoter of $V$. cholerae (Figure 3a) [43]. HlyU binds to the far upstream region of the hlyA promoter, from -195 to $-131 \mathrm{bp}$ relative to the transcription start site of $h l y A$, and activates the transcription. Although the exact mechanism of HlyU-mediated activation is not yet clear in $V$. cholerae, it might function as an anti-repressor, as shown for the $v v h A$ and $r t x A$ genes in $V$. vulnificus (see below) [32,35]. In contrast to HlyU, Fur represses $h l y A$ by binding to a region spanning $-164 \mathrm{bp}$ to $-75 \mathrm{bp}$. Notably, this site is partially overlapped with the HlyU binding site described above, suggesting that Fur binding could exclude the important positive regulator HlyU from the $h l y A$ promoter, thereby enacting negative regulation. In the case of $\mathrm{HapR}$, binding occurs at two different regions: from -158 bp to $-119 \mathrm{bp}$ and $-31 \mathrm{bp}$ to $+3 \mathrm{bp}$. The first HapR binding site is, again, partially overlapped with the HlyU binding site, whereas the second site is overlapped with an RNA polymerase (RNAP)-binding site, namely -10 box and extended -10 region. The occupancy of these regions by HapR probably inhibits the binding of HlyU and RNAP and thus decreases the $h l y A$ transcript level.

The transcriptional regulation mechanism of $v v h A$, a cytolysin/hemolysin gene in $V$. vulnificus, is somewhat different from and more complicated than that of the $h l y A$ in $V$. cholerae. Most important, vohA is co-transcribed with the upstream $v v h B$ gene [31]. Also, a nucleoid-like protein, H-NS, has been found to bind to multiple sites in the $v v h B A$ operator region to silence their expression (Figure 3b) [32,126]. Unlike HapR binding in the hlyA promoter, SmcR, a quorum sensing master regulator in $V$. vulnificus, does not bind directly to the vvhBA promoter. Instead, it indirectly regulates vohBA expression by binding to the hlyU promoter and repressing its transcription [127]. 
a

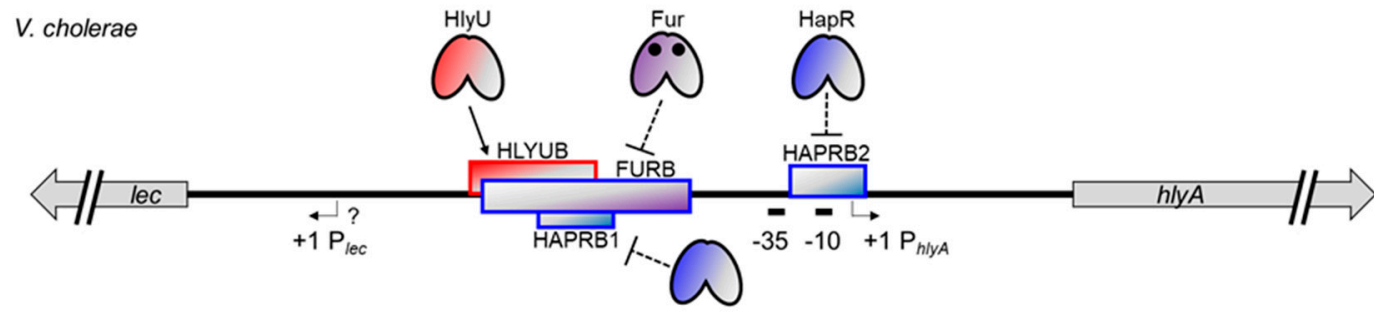

b V. vulnificus
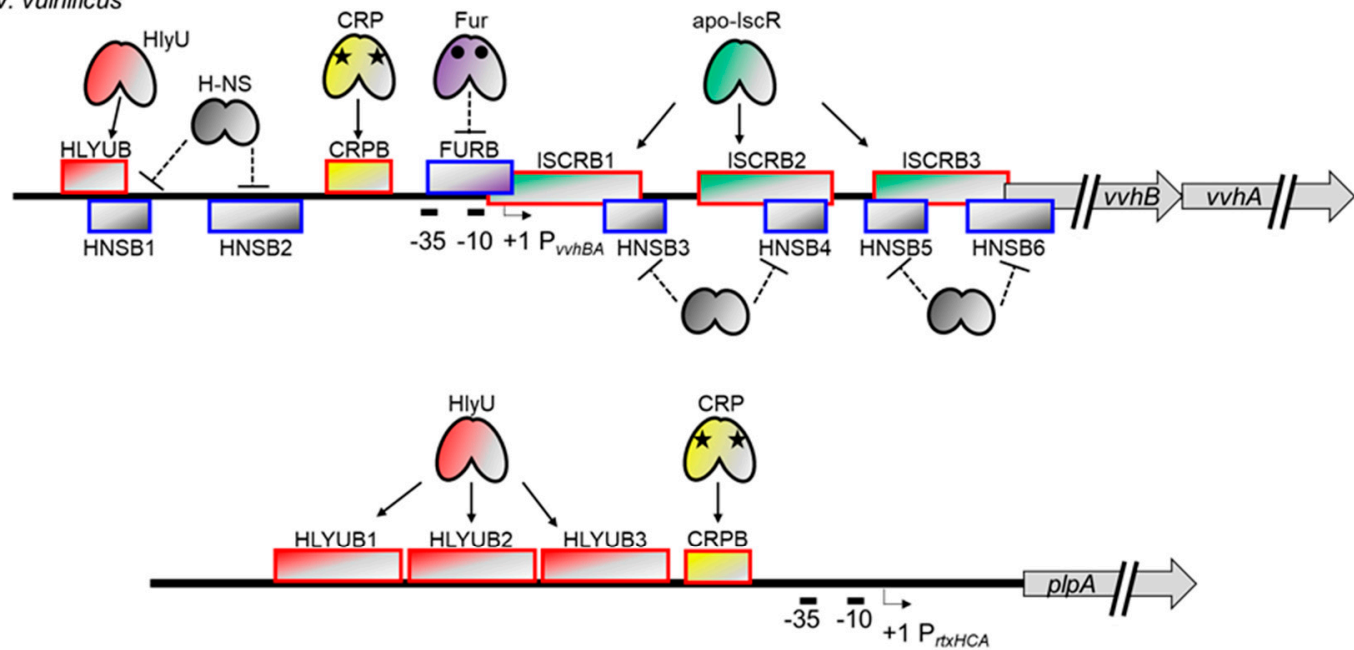

c V. anguillarum

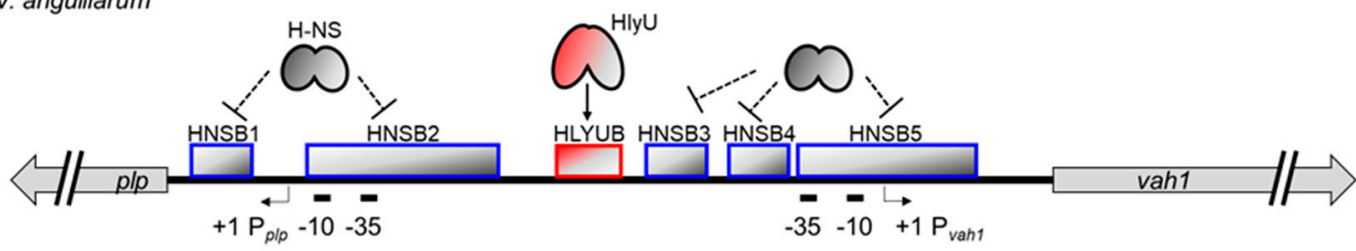

Figure 3. Transcriptional regulation of cytolysin/hemolysin and the secreted phospholipase genes in (a) V. cholerae, (b) V. vulnificus, and (c) V. anguillarum. Note that the phospholipase gene is divergently transcribed from the cytolysin/hemolysin gene in V. cholerae and V. anguillarum, but not in $V$. vulnificus. Transcription start sites and $-10 /-35$ boxes are indicated by bent arrows and thick short lines, respectively. Solid arrows and dotted blunt lines represent the binding of positive and negative regulators, respectively. Binding sites for the positive and negative regulators are indicated by red and blue framed boxes, respectively. Black circles in Fur are irons, whereas black stars in CRP are cAMPs. HLYUB, HlyU binding site; FURB, Fur binding site; HAPRB1, HapR binding site 1; and so on.

Nonetheless, regulation mechanisms similar to those found in $h l y A$ regulation do exist in vvhBA regulation. For example, V. vulnificus HlyU binds directly to the upstream promoter region of vvhBA. This HlyU binding site, spanning from -128 bp to -114 bp relative to the transcription start site of vohBA, partially overlaps with one of the H-NS binding sites described above (Figure $3 b$ ). Therefore, HlyU binding could cause de-repression of vvhBA $[32,127]$. The $V$. vulnificus Fur protein also binds directly to the promoter region of $v v h B A$ and represses its transcription $[128,129]$. In this case, however, the binding site spans from $-32 \mathrm{bp}$ to $+2 \mathrm{bp}$, indicating that Fur binding directly hinders RNAP recruitment, not HlyU binding, to the promoter. It is also worth noting that the location of this Fur binding site is almost the same as the location of the second HapR binding site in the V. cholerae hly $A$ promoter (Figure $3 \mathrm{a}, \mathrm{b}$ ), suggesting that the prevention of RNAP binding via any repressor protein might be a common strategy for hemolysin gene regulation in Vibrio species [43,128].

In addition to Fur, HlyU, and H-NS, two global regulators are also involved in vvhBA regulation in V. vulnificus. First, a CRP protein, when complexed with a cyclic AMP, binds directly to the promoter 
region from -67 to $-50 \mathrm{bp}$ and activates $v v h B A$ expression as a Class I activator (Figure 3b) $[31,32,130]$. Second, an IscR protein, a Fe-S cluster-containing transcriptional regulator, binds directly to three different sites in the $v v h B A$ operator [32]. Intriguingly, all these IscR binding sites are located downstream of the $v v h B A$ transcriptional start site. Nonetheless, these sites are overlapped with the H-NS binding sites, and thus IscR functions as an anti-repressor and enhances $v v h B A$ transcription (Figure 3b) [32].

Relatively little information is available about the transcriptional regulation mechanism of vah1 in V. anguillarum. Nonetheless, both H-NS and HlyU have been revealed to affect vah1 expression by directly binding to the DNA [33,117]. Indeed, H-NS binds to multiple regions of the vah1 promoter, including RNAP binding sites, -10 / -35 boxes, and represses vah1 expression [117]. In contrast, HlyU binds to a single region and functions as a positive regulator [33]. Interestingly, however, the $\mathrm{HlyU}$ binding site does not overlap with any of the H-NS binding sites in the vah1 regulation system (Figure 3c). Perhaps another transcriptional regulator recruited by HlyU functions as an anti-repressor by competing with H-NS for DNA binding and interferes with the H-NS-mediated silencing. It also cannot be ruled out that HlyU binding might hinder the cooperative binding of $\mathrm{H}-\mathrm{NS}$ molecules on the DNA.

\subsection{Transcriptional Regulation of the MARTX Toxin Genes in Vibrio Species}

In Vibrio species, the MARTX toxin gene is in the $r t x$ locus, which consists of two divergently transcribed operons [131,132]. One is $r t x H C A$, which encodes a conserved hypothetical protein, toxin-activating acyltransferase, and the MARTX toxin. The other operon is $r t x B D E$, which encodes atypical T1SS components for MARTX toxin secretion. Boardman and Satchell investigated the growth phase regulation of MARTX toxin activity in $V$. cholerae and discovered that both operons are highly expressed at the exponential phase but not the stationary phase [29]. Although they found no trans-acting regulators involved in this regulation, they successfully presented that a discriminator region downstream of the -10 box of $r t x B D E$ is responsible for the growth phase-dependent regulation of the operon. Because a similar discriminator sequence is also present at the $V$. cholerae rtxHCA promoter, they further suggested that such a stringent sensing element could regulate the transcription of the MARTX toxin gene as well (Figure 4a) [29,133].

The transcriptional regulator proteins for the MARTX toxin gene were first identified in V. vulnificus. Because the $V$. vulnificus hly U gene was preferentially upregulated in in vivo conditions and was critical for pathogenesis [134], Crosa and colleagues hypothesized that genes encoding crucial virulence factors were controlled by this regulator. In a microarray analysis comparing WT and hlyU mutant V. vulnificus, they found decreased expression of $r$ x $\mathrm{HCA}$ in the mutant. Consistent with that, a recombinant $\mathrm{HlyU}$ protein bound directly to the promoter region of $r x \mathrm{HCA}$ (Figure $4 \mathrm{~b}$ ) [42]. They further discovered that $\mathrm{H}-\mathrm{NS}$ also binds to multiple regions of the promoter and silences the operon. Notably, HlyU binding alleviates this H-NS-mediated repression, as in the vvhBA promoter [32,35].

Although little information is available, MARTX toxin gene regulation in $V$. anguillarum appears to be similar to that in $V$. vulnificus. The $V$. anguillarum H-NS binds to six sites in the promoter region of the $V$. anguillarum $r$ x $x$ HCA operon, including the -35 box, and represses transcription (Figure 4c). One of the six sites, however, overlaps with the HlyU binding site, and thus HlyU can function as an anti-repressor of the $V$. anguillarum $r$ x $\mathrm{HCA}$ promoter $[33,117]$.

Recently, additional regulation mechanisms for the MARTX toxin gene have been revealed in both $V$. cholerae and $V$. vulnificus. First, while trying to determine the quorum-controlled small regulatory RNAs in $V$. cholerae, Papenfort and colleagues discovered a vqmR that represses $r t x H C A$ expression by binding to the $5^{\prime}$ UTR of the transcript (Figure 4a) $[135,136]$. Although this post-transcriptional regulation is not conserved in V. vulnificus [135], quorum-mediated repression of $r$ txHCA could still be operating in that strain because the quorum sensing regulator SmcR directly represses $h l y U$, whose product alleviates the H-NS-mediated repression of the $r t x H C A$ [127]. 
a V. cholerae

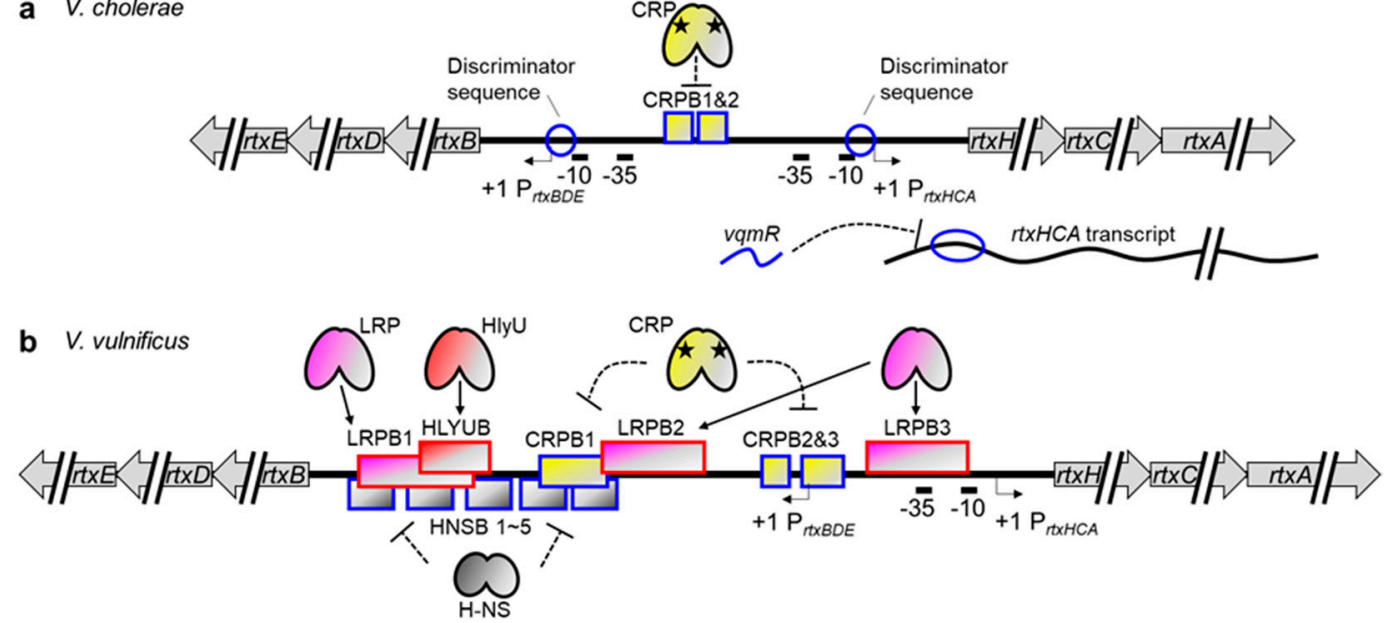

c V. anguillarum

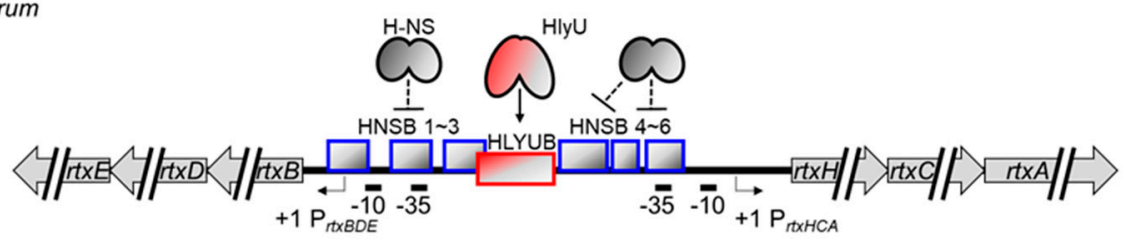

Figure 4. Transcriptional regulation of the MARTX toxin and its secretion system genes in (a) V. cholerae, (b) V. vulnificus, and (c) V. anguillarum. Note that the toxin encoding operon rtxHCA and the secretion system encoding operon $r t x B D E$ are divergently transcribed. Discriminator sequences in the $V$. cholerae rtxHCA and $r t x B D E$ are indicated by blue circles. A vqmR binding site in the V. cholerae rtxHCA transcript is indicated by a blue oval. The others are the same as described in Figure 3.

Second, the leucine-responsive regulatory protein (LRP) and CRP have been found to control rtxHCA in V. vulnificus via direct binding (Figure 4b) [137]. Despite the partial overlap between the LRP and H-NS binding sites, both proteins can bind simultaneously to the rtxHCA promoter. In fact, LRP-mediated activation of $r t x H C A$ occurred independently of H-NS, indicating that LRP is an authentic activator, not an anti-repressor like HlyU, for the $V$. vulnificus MARTX toxin gene. It has also been found that the cAMP-complexed CRP protein binds to three different upstream regions of the transcription start site of $r t x H C A$ and negatively regulates transcription [137]. Those authors speculated that this could be due to a hindered promoter-clearance of RNAP because CRP retains RNAP via protein-protein interaction. This rather unusual regulation by CRP is not unique to this particular case but has also been reported in the V. cholerae rtxBDE promoter (Figure 4a) [138]. Notably, however, the $V$. cholerae $r t x H C A$ operon was constitutively transcribed independently of CRP [138], suggesting that the CRP-mediated regulation of the $r t x$ genes is similar but not strictly conserved among different Vibrio species.

Another thing should be noticed here is that the transcription start site of the V. vulnificus rt $x B D E$ is located at the third CRP binding site (CRPB3) (Figure 4b) [132]. Thus, most of the LRP, CRP, and HlyU binding sites are downstream of the transcription start site of $r x B D E$. Nonetheless, the roles of those transcriptional regulators on $r t x B D E$ expression have not yet been elucidated. For a comprehensive understanding of the regulation of MARTX toxin secretion, it also needs be determined whether those regulators function as roadblocks or anti-repressors for $r t x B D E$ expression.

\subsection{Transcriptional Regulation of Secreted Phospholipase Genes in Vibrio Species}

In contrast to the two exotoxins just described, the transcriptional regulation of secreted phospholipases has not been studied in detail. In V. cholerae and V. anguillarum, the secreted phospholipase genes (lec and $p l p$, respectively) are divergently transcribed from the cytolysin/hemolysin 
genes (hlyA and vah1, respectively), suggesting that two exotoxin genes could share a regulatory region and thus be controlled by a common transcriptional regulation mechanism (Figure 3a,c). Indeed, it was reported that the expression of the plp gene in $V$. anguillarum is directly repressed by H-NS and that repression is suppressed by HlyU binding, like the vah1 gene $[33,117]$. Although no such definitive study has been done, the same gene synteny for lec and $h l y A$ in $V$. cholerae strongly suggest that the lec gene is similarly regulated with hlyA by HlyU and other repressors such as Fur and HapR $[43,105,114]$.

In $V$. vulnificus, however, the phospholipase gene $p l p A$ is not physically linked to cytolysin/hemolysin gene $v v h B A$ and is located at an entirely different site on the chromosome with its own regulatory region (Figure 3b). Despite that unique gene structure, the V. vulnificus plpA is also under the control of HlyU [36]. Indeed, HlyU binding occurs at three consecutive sites (from -191 $\mathrm{bp}$ to $-157 \mathrm{bp},-151 \mathrm{bp}$ to $-128 \mathrm{bp}$, and $-126 \mathrm{bp}$ to $-93 \mathrm{bp}$ relative to the transcription start site of $p l p A$ ) in the region upstream of the $p l p A$ promoter. However, no evidence for $\mathrm{H}-\mathrm{NS}$ binding has been found, indicating that $\mathrm{HlyU}$, in this case, may function as an activator not an anti-repressor. It has also been found that the CRP protein binds to the region from $-82 \mathrm{bp}$ to $-57 \mathrm{bp}$ and executes positive regulation as a Class I activator [36]. Notably, no regulation hierarchy or competition has been found between HlyU and CRP. Instead, they activate the $p l p A$ gene in an additive manner.

\subsection{Spatiotemporal Regulation of Exotoxin Genes for Successful Pathogenesis}

As summarized above, diverse transcriptional regulators cooperate to control three major exotoxin genes in pathogenic Vibrio species. These include HlyU, H-NS, Fur, HapR (or its homologues like SmcR), $\mathrm{CRP}$, IscR, and LRP. The small regulatory RNA vqmR and discriminator sequences in the promoters have also been found in the regulation system.

Why do pathogens use these diverse factors in exotoxin production? First, because the genes should be expressed preferentially when Vibrio invades the host. The major role of all three exotoxins is attacking host cells or tissues and using their destructive activities to dampen host defense systems. Therefore, toxin production is not required if Vibrio lives freely in the ocean, and needless production would squander energy. This is particularly critical for MARTX toxin production because this toxin is usually encoded by the longest gene of Vibrio species [78]. Thus, the nucleoid-like protein H-NS is used in most of these exotoxin gene promoters to tightly repress them (Figure 5a) [32,117,127,137].

When Vibrio encounters a host, however, this H-NS-mediated silencing should be alleviated, and HlyU acts at that stage as an anti-repressor (Figure 5a). Indeed, HlyU has a higher affinity to the target DNA compared with H-NS, and thus can outcompete the H-NS $[32,35,117]$. Notably, in some promoters, like the $V$. cholerae hly $A$ and $V$. vulnificus $p l p A$, where no H-NS binding has been found, HlyU also acts as an activator [36,43]. These results confer a critical role on HlyU, over H-NS, as a key virulence regulator in pathogenic Vibrio species. Because $h l y U$ is preferentially expressed in in vivo conditions [134], all three exotoxins can escape H-NS-mediated silencing when Vibrio invades a host. Then, the genes would be ready for the next round of regulation conducted by their own distinct transcriptional regulators.

Second, even if Vibrio has entered a host, each exotoxin must be expressed at the right time and in the right place because each exotoxin has a distinct function. The MARTX toxin dampens immune-related signaling in host cells and damages protective barriers in the host gut $[78,80]$. Meanwhile, cytolysin/hemolysin lyses erythrocytes to liberate iron-containing proteins and induces destructive inflammation by activating cytokine production from immune cells [47,48,71,72]. Similarly, secreted phospholipases lyse host cells, facilitating necrotic cell death and subsequent inflammation [36]. Given those functions, the MARTX toxin should be expressed from the early stage of infection, when Vibrio encounters the host gut epithelium. In contrast, cytolysin/hemolysin and phospholipase are necessary at a relatively later stage of infection, when Vibrio has overcome the host's initial immune responses and started to bloom to overwhelm the host. 
a

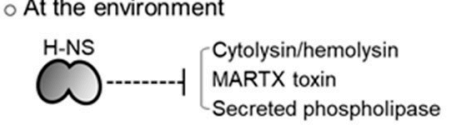

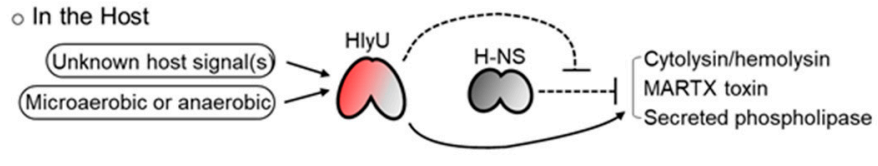

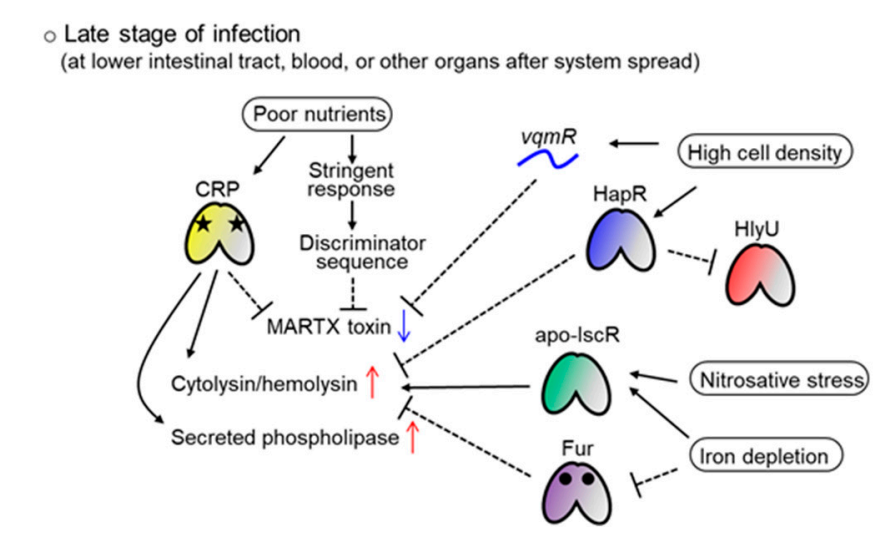

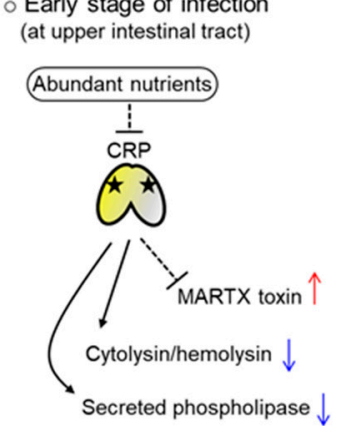

(n)

Figure 5. Spatiotemporal regulation of the Vibrio exotoxin genes by diverse transcriptional regulators. (a) In a non-host environment, exotoxin gene expression is repressed by H-NS. When Vibrio encounters a host, unknown host signal(s) induce HlyU production, de-repressing the H-NS-mediated repression of exotoxins. HlyU might also sense microaerobic or anaerobic conditions in the host. V. cholerae cytolysin/hemolysin and $V$. vulnificus secreted phospholipase expression are also activated by HlyU. (b) Exotoxins are differentially regulated depending on the local host conditions. At the early stage of infection, abundant nutrients inactivate CRP, increasing the MARTX toxin but decreasing cytolysin/hemolysin and secreted phospholipase. At the late stage of infection, poor nutrient conditions are conveyed by CRP and discriminator sequences, decreasing the MARTX toxin but increasing cytolysin/hemolysin and secreted phospholipase. Nitrosative stress and iron depletion are sensed by IscR and Fur, resulting in the production of cytolysin/hemolysin. When the pathogen overwhelms the host at the very late stage of infection, the quorum sensing master regulator HapR and quorum-regulated sRNA $v q m R$ repress the expression of MARTX toxin and cytolysin/hemolysin, respectively. HapR (or its homologue, SmcR) also represses HlyU, terminating the HlyU-mediated de-repression of exotoxin genes.

Because local conditions differ spatiotemporally in the host, Vibrio should sense those differences to control exotoxin expression. It is in this context that the role of the diverse transcriptional regulators can be explained. For example, CRP can regulate genes depending on local nutrient levels. Relatively more nutrients would be present in the host's upper intestinal tract (duodenum and jejunum) than in lower sites (ileum). When Vibrio reaches the upper site after ingestion with contaminated foods, those relatively abundant nutrients, such as glucose, could lead the depletion of cAMP in the bacterium. Consequently, cAMP-unbound, inactivated CRPs would be released from the rtxHCA and rtxBDE promoters, allowing the expression and secretion of the MARTX toxin (Figure 5b) [137,138]. Conversely, toxin expression would be repressed by cAMP-bound CRPs when Vibrio encounters nutrient-poor conditions in the lower intestinal tract or at the late stage of infection. The discriminator sequences found in the $V$. cholerae rtx operons might also contribute to this kind of nutrient level-dependent regulation of the MARTX toxin. In contrast to the $r t x H C A$, both the vvhBA and plpA genes are activated by CRP in $V$. vulnificus $[32,36]$. Therefore, those two exotoxins could be expressed at the late stage of infection, when nutrients are relatively depleted (Figure 5b).

Other examples are IscR and Fur. If Vibrio species, especially V. vulnificus, invade a host's blood system, the pathogens will face harsh conditions, such as iron depletion and nitrosative stress, due to the host's iron-sequestering system and NO-producing immune cells (macrophages and neutrophils) [139]. Because many more apo-IscRs (IscR with no Fe-S cluster) are produced under iron starvation and 
nitrosative stress conditions, the $v v h B A$ regulatory region will be occupied by apo-IscR instead of H-NS in such conditions [32,140]. In that way, the H-NS-mediated silencing of vohBA can be alleviated, allowing the Vibrio to overcome the stresses and even counterattack the host using cytolysin/hemolysin (Figure 5b). Similarly, the Fur-mediated repression of the V. vulnificus vvhBA and V. cholerae hlyA will be relieved under iron depletion conditions because apo-Fur (Fur without iron) cannot bind to the target DNAs (Figure 5b) [32,128].

Finally, quorum sensing also contributes to the precise regulation of exotoxin expression. If the invading pathogens successfully colonize and overwhelm the host, their population will expand significantly. It is tempting to speculate that no more energy-consuming and destructive exotoxins such as MARTX might be necessary at that very late stage of infection. In this context, both HapRand $v q m R$-mediated repression of $V$. cholerae hly $A$ and $r t x H C A$, respectively, are significant at a high bacterial cell density $[43,135]$. Furthermore, because the $h l y U$ genes in $V$. cholerae and V. vulnificus are directly repressed by HapR and $S m c R$, respectively, all three exotoxins could be controlled by quorum signals in a similar way (Figure $5 b)[43,127]$.

\section{Anti-Virulence Strategy Targeting HlyU and Future Directions}

Considering the increasing threat of antibiotic resistance, alternative strategies to combat bacterial pathogens urgently need to be developed [141]. This is also true of pathogenic Vibrio species because a tremendous amount of antibiotics is currently used in aquaculture worldwide [142,143]. One alternative is an anti-virulence strategy that targets bacterial virulence potential instead of viability [144,145]. Indeed, a treatment that inhibited the expression, secretion, or activity of virulence factors such as exotoxins could disarm the pathogen and facilitate pathogen elimination from the host.

As reviewed in this article, the key virulence regulator HlyU coordinately controls three major exotoxins in pathogenic Vibrio species. Although not summarized here, it also regulates T3SS1 genes in V. parahaemolyticus via the transcription factor ExsA [146]. Therefore, HlyU is a fascinating target for developing anti-virulence agents to impede the cooperative consequences of the exotoxins in pathogenic Vibrio species. Compared with the WT V. vulnificus, a hlyU deletion mutant indeed showed a 10- to 50-fold increase in $\mathrm{LD}_{50}$ in a mouse infection model [134]. Because HlyU binds directly to the toxin gene promoters and positively regulates them as an anti-repressor or activator, inhibiting the DNA binding activity of HlyU could reduce virulence.

Recently, three small molecules have been identified as HlyU inhibitors [147-149]. Although they have no structural similarity, both $\mathrm{N}$-(4-oxo-4H-thieno[3,4-c]chromen-3-yl)-3phenylprop-2-ynamide (CM14) and 2', $4^{\prime}$-dihydroxychalcone interfere in the binding between HlyU and the V. vulnificus rtxA gene promoter thus decrease MARTX toxin expression [148,149]. No such DNA binding defect has been shown in the fursultiamine hydrochloride-treated HlyU, but the expression of the rtxA gene was also significantly affected in that case [147]. Consistent with HlyU's global regulatory function in Vibrio species, these HlyU inhibitors, especially CM14, exhibited strong anti-virulence effects against various pathogenic Vibrio species by inhibiting expression of multiple exotoxin genes [148,149].

Moving forward, researchers need to keep pursuing a comprehensive understanding of the virulence factors and their regulation in pathogenic Vibrio species to establish more effective and practical anti-virulence strategies. First, the characteristics and regulation mechanisms of the three exotoxins still need to be clearly identified. What mediates host cell binding of the MARTX toxin and secreted phospholipases? Why and how does the $V$. vulnificus MARTX toxin, but not the $V$. cholerae MARTX toxin, lyse host cells? Is it because of different expression levels caused by distinct regulation? Is the expression of $r t x H C A$ in $V$. cholerae and other Vibrio species also controlled by nutrient availability via CRP or LRP, as found in $V$. vulnificus?

Second, HlyU-mediated virulence regulation should be further examined. Are any other exotoxins directly regulated by HlyU? How is their regulation coordinated with that of the three exotoxins reviewed here? Does HlyU really sense in vivo oxygen levels to regulate its regulon? Researchers 
also need to identify the conditions that cause HlyU to be preferentially expressed in vivo, initiating a virulence cascade.

Third, the exact modes of action of the HlyU inhibitors need to be revealed. Although it was identified that part of CM14 is covalently attached to a cysteine residue of HlyU, neither the initial interaction between CM14 and HlyU nor the binding mode of CM14 to HlyU has been clearly shown at the atomic level with its three dimensional structure [149]. That information would enable us to design a better HlyU inhibitor with improved activity and bioavailability compared with current treatments.

Last, not only the HlyU inhibitor but also inhibitors targeting other transcriptional regulators or the exotoxins themselves should be screened and identified. For example, researchers could screen for a small molecule that prevents iron sensing by Fur or nitrosative stress sensing by IscR. Similarly, the diverse quorum sensing inhibitors already found in multiple Vibrio species could be combined with those inhibitors to dysregulate the entire exotoxin gene expression system [150,151]. In addition, molecules that interfere in either the binding of cytolysin/hemolysin to the host cell membrane or the translocation of the MARTX effector domains into host cell cytosol could be combined. Because both spatiotemporal expression and the precise activity of multiple exotoxins are critical for successful pathogenesis of Vibrio species, such combinations could offer more-effective virulence attenuation than a HlyU inhibitor alone.

In conclusion, the functions and transcriptional regulation mechanisms of cytolysin/hemolysin, the MARTX toxin, and secreted phospholipases in pathogenic Vibrio species have been reviewed here. Notably, the transcriptional regulator HlyU coordinates the expression of all three exotoxins as an anti-repressor or activator. Despite this HlyU-mediated coordination, however, the expression of the exotoxin genes remains distinct. This is because diverse transcriptional regulators sense various host-driven environmental changes and then precisely regulate each exotoxin gene in a spatiotemporal manner. Along with the results from the research suggested above, this information will enable us to fight against pathogenic Vibrio species in the upcoming post-antibiotic era. Moreover, the strategy disrupting a coordinated but distinct regulation system of exotoxins could be applied to other pathogenic bacteria.

Funding: This work was supported by the National Research Foundation (NRF) of Korea funded by the Ministry of Science and ICT of Korea (NRF-2020R1F1A1070168) and by a grant (20162MFDS142) from the Ministry of Food and Drug Safety in 2020.

Conflicts of Interest: I declare no conflict of interest. The funders had no role in the design of the study; in the collection, analyses, or interpretation of data; in the writing of the manuscript, or in the decision to publish the results.

\section{References}

1. Thompson, F.L.; Iida, T.; Swings, J. Biodiversity of vibrios. Microbiol. Mol. Biol. Rev. 2004, 68, $403-431$. [CrossRef] [PubMed]

2. Boyd, E.F.; Carpenter, M.R.; Chowdhury, N.; Cohen, A.L.; Haines-Menges, B.L.; Kalburge, S.S.; Kingston, J.J.; Lubin, J.B.; Ongagna-Yhombi, S.Y.; Whitaker, W.B. Post-Genomic Analysis of Members of the Family Vibrionaceae. Microbiol. Spectr. 2015, 3, 1-26. [CrossRef] [PubMed]

3. Aguilera-Rivera, D.; Prieto-Davó, A.; Rodríguez-Fuentes, G.; Escalante-Herrera, K.S.; Gaxiola, G. A vibriosis outbreak in the Pacific white shrimp, Litopenaeus vannamei reared in biofloc and clear seawater. J. Invertebr. Pathol. 2019, 167. [CrossRef] [PubMed]

4. Cao, J.; Zhang, J.; Ma, L.; Li, L.; Zhang, W.; Li, J. Identification of fish source Vibrio alginolyticus and evaluation of its bacterial ghosts vaccine immune effects. MicrobiologyOpen 2018, 7, e00576. [CrossRef] [PubMed]

5. Tison, D.L.; Nishibuchi, M.; Greenwood, J.D.; Seidler, R.J. Vibrio vulnificus biogroup 2: New biogroup pathogenic for eels. Appl. Environ. Microbiol. 1982, 44, 640-646. [CrossRef]

6. Biosca, E.G.; Oliver, J.D.; Amaro, C. Phenotypic characterization of Vibrio vulnificus biotype 2, a lipopolysaccharide-based homogeneous O serogroup within Vibrio vulnificus. Appl. Environ. Microbiol. 1996, 62, 918-927. [CrossRef] 
7. Bruto, M.; James, A.; Petton, B.; Labreuche, Y.; Chenivesse, S.; Alunno-Bruscia, M.; Polz, M.F.; Le Roux, F. Vibrio crassostreae, a benign oyster colonizer turned into a pathogen after plasmid acquisition. ISME J. 2017, 11, 1043-1052. [CrossRef]

8. Egidius, E. Vibriosis: Pathogenicity and pathology. A review. Aquaculture 1987, 67, 15-28. [CrossRef]

9. Baker-Austin, C.; Oliver, J.D.; Alam, M.; Ali, A.; Waldor, M.K.; Qadri, F.; Martinez-Urtaza, J. Vibrio spp. infections. Nat. Rev. Dis. Primers 2018, 4, 8. [CrossRef]

10. Krebs, S.J.; Taylor, R.K. Protection and attachment of Vibrio cholerae mediated by the toxin-coregulated pilus in the infant mouse model. J. Bacteriol. 2011, 193, 5260-5270. [CrossRef]

11. Kirn, T.J.; Lafferty, M.J.; Sandoe, C.M.; Taylor, R.K. Delineation of pilin domains required for bacterial association into microcolonies and intestinal colonization by Vibrio cholerae. Mol. Microbiol. 2000, 35, 896-910. [CrossRef] [PubMed]

12. Taylor, R.K.; Miller, V.L.; Furlong, D.B.; Mekalanos, J.J. Use of phoA gene fusions to identify a pilus colonization factor coordinately regulated with cholera toxin. Proc. Natl. Acad. Sci. USA 1987, 84, 2833-2837. [CrossRef] [PubMed]

13. Arezes, J.; Jung, G.; Gabayan, V.; Valore, E.; Ruchala, P.; Gulig, P.A.; Ganz, T.; Nemeth, E.; Bulut, Y. Hepcidin-Induced Hypoferremia Is a Critical Host Defense Mechanism against the Siderophilic Bacterium Vibrio vulnificus. Cell Host Microbe 2015, 17, 47-57. [CrossRef] [PubMed]

14. Litwin, C.M.; Rayback, T.W.; Skinner, J. Role of catechol siderophore synthesis in Vibrio vulnificus virulence. Infect. Immun. 1996, 64, 2834-2838. [CrossRef]

15. Webster, A.C.; Litwin, C.M. Cloning and characterization of vuuA, a gene encoding the Vibrio vulnificus ferric vulnibactin receptor. Infect. Immun. 2000, 68, 526-534. [CrossRef]

16. Kim, I.H.; Shim, J.I.; Lee, K.E.; Hwang, W.; Kim, I.J.; Choi, S.H.; Kim, K.S. Nonribosomal peptide synthase is responsible for the biosynthesis of siderophore in Vibrio vulnificus MO6-24/O. J. Microbiol. Biotechnol. 2008, $18,35-42$.

17. Tan, W.; Verma, V.; Jeong, K.; Kim, S.; Jung, C.-H.; Lee, S.; Rhee, J. Molecular characterization of vulnibactin biosynthesis in Vibrio vulnificus indicates the existence of an alternative siderophore. Front. Microbiol. 2014, 5, 1. [CrossRef]

18. Yoshida, S.; Ogawa, M.; Mizuguchi, Y. Relation of capsular materials and colony opacity to virulence of Vibrio vulnificus. Infect. Immun. 1985, 47, 446-451. [CrossRef]

19. Jones, M.K.; Oliver, J.D. Vibrio vulnificus: Disease and pathogenesis. Infect. Immun. 2009, 77, $1723-1733$. [CrossRef]

20. Brown, S.A.; Palmer, K.L.; Whiteley, M. Revisiting the host as a growth medium. Nat. Rev. Microbiol. 2008, 6, 657-666. [CrossRef]

21. Almagro-Moreno, S.; Boyd, E.F. Sialic Acid Catabolism Confers a Competitive Advantage to Pathogenic Vibrio cholerae in the Mouse Intestine. Infect. Immun. 2009, 77, 3807-3816. [CrossRef] [PubMed]

22. Jeong, H.G.; Oh, M.H.; Kim, B.S.; Lee, M.Y.; Han, H.J.; Choi, S.H. The capability of catabolic utilization of $\mathrm{N}$-acetylneuraminic acid, a sialic acid, is essential for Vibrio vulnificus pathogenesis. Infect. Immun. 2009, 77, 3209-3217. [CrossRef] [PubMed]

23. Kim, B.S.; Hwang, J.; Kim, M.H.; Choi, S.H. Cooperative regulation of the Vibrio vulnificus nan gene cluster by NanR protein, cAMP receptor protein, and N-acetylmannosamine 6-phosphate. J. Biol. Chem. 2011, 286, 40889-40899. [CrossRef] [PubMed]

24. Hwang, J.; Kim, B.S.; Jang, S.Y.; Lim, J.G.; You, D.J.; Jung, H.S.; Oh, T.K.; Lee, J.O.; Choi, S.H.; Kim, M.H. Structural insights into the regulation of sialic acid catabolism by the Vibrio vulnificus transcriptional repressor NanR. Proc. Natl. Acad. Sci. USA 2013, 110, E2829-E2837. [CrossRef] [PubMed]

25. Do Vale, A.; Cabanes, D.; Sousa, S. Bacterial Toxins as Pathogen Weapons Against Phagocytes. Front. Microbiol. 2016, 7, 42. [CrossRef]

26. Bhavsar, A.P.; Guttman, J.A.; Finlay, B.B. Manipulation of host-cell pathways by bacterial pathogens. Nature 2007, 449, 827-834. [CrossRef]

27. Olivier, V.; Haines, G.K., 3rd; Tan, Y.; Satchell, K.J. Hemolysin and the multifunctional autoprocessing RTX toxin are virulence factors during intestinal infection of mice with Vibrio cholerae El Tor O1 strains. Infect. Immun. 2007, 75, 5035-5042. [CrossRef]

28. Tsou, A.M.; Zhu, J. Quorum sensing negatively regulates hemolysin transcriptionally and posttranslationally in Vibrio cholerae. Infect. Immun. 2010, 78, 461-467. [CrossRef] 
29. Boardman, B.K.; Meehan, B.M.; Fullner Satchell, K.J. Growth phase regulation of Vibrio cholerae RTX toxin export. J. Bacteriol. 2007, 189, 1827-1835. [CrossRef]

30. Gray, L.D.; Kreger, A.S. Purification and characterization of an extracellular cytolysin produced by Vibrio vulnificus. Infect. Immun. 1985, 48, 62-72. [CrossRef]

31. Choi, H.K.; Park, N.Y.; Kim, D.-i.; Chung, H.J.; Ryu, S.; Choi, S.H. Promoter Analysis and Regulatory Characteristics of vvhBA Encoding Cytolytic Hemolysin of Vibrio vulnificus. J. Biol. Chem. 2002, 277, 47292-47299. [CrossRef] [PubMed]

32. Choi, G.; Jang, K.K.; Lim, J.G.; Lee, Z.-W.; Im, H.; Choi, S.H. The transcriptional regulator IscR integrates host-derived nitrosative stress and iron starvation in activation of the vvhBA operon in Vibrio vulnificus. J. Biol. Chem. 2020, 295, 5350-5361. [CrossRef] [PubMed]

33. Li, L.; Mou, X.; Nelson, D.R. HlyU is a positive regulator of hemolysin expression in Vibrio anguillarum. J. Bacteriol. 2011, 193, 4779-4789. [CrossRef] [PubMed]

34. Park, J.; Kim, S.M.; Jeong, H.G.; Choi, S.H. Regulatory characteristics of the Vibrio vulnificus rtxHCA operon encoding a MARTX toxin. J. Microbiol. 2012, 50, 878-881. [CrossRef] [PubMed]

35. Liu, M.; Naka, H.; Crosa, J.H. HlyU acts as an H-NS antirepressor in the regulation of the RTX toxin gene essential for the virulence of the human pathogen Vibrio vulnificus CMCP6. Mol. Microbiol. 2009, 72, 491-505. [CrossRef] [PubMed]

36. Jang, K.K.; Lee, Z.W.; Kim, B.; Jung, Y.H.; Han, H.J.; Kim, M.H.; Kim, B.S.; Choi, S.H. Identification and characterization of Vibrio vulnificus plpA encoding a phospholipase A2 essential for pathogenesis. J. Biol. Chem. 2017, 292, 17129-17143. [CrossRef] [PubMed]

37. Bang, Y.B.; Lee, S.E.; Rhee, J.H.; Choi, S.H. Evidence that Expression of the Vibrio vulnificus Hemolysin Gene Is Dependent on Cyclic AMP and Cyclic AMP Receptor Protein. J. Biol. Chem. 1999, 181, 7639-7642. [CrossRef]

38. Miyoshi, S.-i.; Okamoto, K.; Takahashi, E. Vibriolysin. In Handbook of Proteolytic Enzymes; Rawlings, N.D., Salvesen, G., Eds.; Academic Press: Cambridge, MA, USA, 2013; pp. 579-582.

39. Miyoshi, S.; Wakae, H.; Tomochika, K.; Shinoda, S. Functional domains of a zinc metalloprotease from Vibrio vulnificus. J. Bacteriol. 1997, 179, 7606-7609. [CrossRef]

40. Jeong, H.G.; Satchell, K.J. Additive function of Vibrio vulnificus MARTX (Vv) and VvhA cytolysins promotes rapid growth and epithelial tissue necrosis during intestinal infection. PLoS Pathog. 2012, 8, e1002581. [CrossRef]

41. Lee, J.H.; Kim, M.W.; Kim, B.S.; Kim, S.M.; Lee, B.C.; Kim, T.S.; Choi, S.H. Identification and characterization of the Vibrio vulnificus rtxA essential for cytotoxicity in vitro and virulence in mice. J. Microbiol. 2007, 45, 146-152.

42. Liu, M.; Alice, A.F.; Naka, H.; Crosa, J.H. The HlyU protein is a positive regulator of $r t x A 1$, a gene responsible for cytotoxicity and virulence in the human pathogen Vibrio vulnificus. Infect. Immun. 2007, 75, 3282-3289. [CrossRef] [PubMed]

43. Gao, H.; Xu, J.; Lu, X.; Li, J.; Lou, J.; Zhao, H.; Diao, B.; Shi, Q.; Zhang, Y.; Kan, B. Expression of Hemolysin Is Regulated Under the Collective Actions of HapR, Fur, and HlyU in Vibrio cholerae El Tor Serogroup O1. Front. Microbiol. 2018, 9, 1310. [CrossRef]

44. Miyoshi, S. Extracellular proteolytic enzymes produced by human pathogenic vibrio species. Front. Microbiol. 2013, 4, 339. [CrossRef] [PubMed]

45. Benitez, J.A.; Silva, A.J. Vibrio cholerae hemagglutinin (HA)/protease: An extracellular metalloprotease with multiple pathogenic activities. Toxicon 2016, 115, 55-62. [CrossRef] [PubMed]

46. Elgaml, A.; Miyoshi, S.I. Regulation systems of protease and hemolysin production in Vibrio vulnificus. Microbiol. Immunol. 2017, 61, 1-11. [CrossRef] [PubMed]

47. Iida, T.; Honda, T. Hemolysins Produced by Vibrios. J. Toxicol. Toxin Rev. 1997, 16, 215-227. [CrossRef]

48. Zhang, X.-H.; Austin, B. Haemolysins in Vibrio species. J. Appl. Microbiol. 2005, 98, 1011-1019. [CrossRef]

49. Skaar, E.P. The Battle for Iron between Bacterial Pathogens and Their Vertebrate Hosts. PLoS Pathog. 2010, 6, e1000949. [CrossRef]

50. Zughaier, S.M.; Cornelis, P. Editorial: Role of Iron in Bacterial Pathogenesis. Front. Cell. Infect. Microbiol. 2018, 8, 344. [CrossRef]

51. Joseph, S.W.; Colwell, R.R.; Kaper, J.B. Vibrio parahaemolyticus and related halophilic Vibrios. Crit. Rev. Microbiol. 1982, 10, 77-124. [CrossRef] 
52. Takeda, Y. Thermostable direct hemolysin of Vibrio parahaemolyticus. Pharmacol. Ther. 1982, 19, $123-146$. [CrossRef]

53. Honda, T.; Ni, Y.X.; Miwatani, T. Purification and characterization of a hemolysin produced by a clinical isolate of Kanagawa phenomenon-negative Vibrio parahaemolyticus and related to the thermostable direct hemolysin. Infect. Immun. 1988, 56, 961-965. [CrossRef]

54. Ichinose, Y.; Yamamoto, K.; Nakasone, N.; Tanabe, M.J.; Takeda, T.; Miwatani, T.; Iwanaga, M. Enterotoxicity of El Tor-like hemolysin of non-O1 Vibrio cholerae. Infect. Immun. 1987, 55, 1090-1093. [CrossRef] [PubMed]

55. Saka, H.A.; Bidinost, C.; Sola, C.; Carranza, P.; Collino, C.; Ortiz, S.; Echenique, J.R.; Bocco, J.L. Vibrio cholerae cytolysin is essential for high enterotoxicity and apoptosis induction produced by a cholera toxin gene-negative $V$. cholerae non-O1, non-O139 strain. Microb. Pathog. 2008, 44, 118-128. [CrossRef] [PubMed]

56. Olson, R.; Gouaux, E. Vibrio cholerae cytolysin is composed of an alpha-hemolysin-like core. Protein Sci. 2003, 12, 379-383. [CrossRef] [PubMed]

57. Yamamoto, K.; Wright, A.C.; Kaper, J.B.; Morris, J.G., Jr. The cytolysin gene of Vibrio vulnificus: Sequence and relationship to the Vibrio cholerae E1 Tor hemolysin gene. Infect. Immun. 1990, 58, 2706-2709. [CrossRef]

58. Hirono, I.; Masuda, T.; Aoki, T. Cloning and detection of the hemolysin gene of Vibrio anguillarum. Microb. Pathog. 1996, 21, 173-182. [CrossRef]

59. Kim, G.T.; Lee, J.Y.; Huh, S.H.; Yu, J.H.; Kong, I.S. Nucleotide sequence of the vmhA gene encoding hemolysin from Vibrio mimicus. Biochim. Biophys. Acta 1997, 1360, 102-104. [CrossRef]

60. Parker, M.W.; Buckley, J.T.; Postma, J.P.; Tucker, A.D.; Leonard, K.; Pattus, F.; Tsernoglou, D. Structure of the Aeromonas toxin proaerolysin in its water-soluble and membrane-channel states. Nature 1994, 367, $292-295$. [CrossRef]

61. Dal Peraro, M.; van der Goot, F.G. Pore-forming toxins: Ancient, but never really out of fashion. Nat. Rev. Microbiol. 2016, 14, 77-92. [CrossRef]

62. Bruggisser, J.; Tarek, B.; Wyder, M.; Muller, P.; von Ballmoos, C.; Witz, G.; Enzmann, G.; Deutsch, U.; Engelhardt, B.; Posthaus, H. CD31 (PECAM-1) Serves as the Endothelial Cell-Specific Receptor of Clostridium perfringens beta-Toxin. Cell Host Microbe 2020, 28, 69-78.e6. [CrossRef] [PubMed]

63. Yamamoto, K.; Ichinose, Y.; Shinagawa, H.; Makino, K.; Nakata, A.; Iwanaga, M.; Honda, T.; Miwatani, T. Two-step processing for activation of the cytolysin/hemolysin of Vibrio cholerae O1 biotype El Tor: Nucleotide sequence of the structural gene $(h l y A)$ and characterization of the processed products. Infect. Immun. 1990, 58, 4106-4116. [CrossRef] [PubMed]

64. Nagamune, K.; Yamamoto, K.; Naka, A.; Matsuyama, J.; Miwatani, T.; Honda, T. In vitro proteolytic processing and activation of the recombinant precursor of El Tor cytolysin/hemolysin (pro-HlyA) of Vibrio cholerae by soluble hemagglutinin/protease of $V$. cholerae, trypsin, and other proteases. Infect. Immun. 1996, 64, 4655-4658. [CrossRef] [PubMed]

65. Valeva, A.; Walev, I.; Weis, S.; Boukhallouk, F.; Wassenaar, T.M.; Endres, K.; Fahrenholz, F.; Bhakdi, S.; Zitzer, A. A cellular metalloproteinase activates Vibrio cholerae pro-cytolysin. J. Biol. Chem. 2004, 279, 25143-25148. [CrossRef]

66. Nagamune, K.; Yamamoto, K.; Honda, T. Intramolecular chaperone activity of the pro-region of Vibrio cholerae El Tor cytolysin. J. Biol. Chem. 1997, 272, 1338-1343. [CrossRef]

67. De, S.; Kaus, K.; Sinclair, S.; Case, B.C.; Olson, R. Structural basis of mammalian glycan targeting by Vibrio cholerae cytolysin and biofilm proteins. PLoS Pathog. 2018, 14, e1006841. [CrossRef]

68. Levan, S.; De, S.; Olson, R. Vibrio cholerae cytolysin recognizes the heptasaccharide core of complex N-glycans with nanomolar affinity. J. Mol. Biol. 2013, 425, 944-957. [CrossRef]

69. Rai, A.K.; Paul, K.; Chattopadhyay, K. Functional mapping of the lectin activity site on the beta-prism domain of Vibrio cholerae cytolysin: Implications for the membrane pore-formation mechanism of the toxin. J. Biol. Chem. 2013, 288, 1665-1673. [CrossRef]

70. Khilwani, B.; Chattopadhyay, K. Signaling beyond Punching Holes: Modulation of Cellular Responses by Vibrio cholerae Cytolysin. Toxins 2015, 7, 3344-3358. [CrossRef]

71. Toma, C.; Higa, N.; Koizumi, Y.; Nakasone, N.; Ogura, Y.; McCoy, A.J.; Franchi, L.; Uematsu, S.; Sagara, J.; Taniguchi, S.; et al. Pathogenic Vibrio activate NLRP3 inflammasome via cytotoxins and TLR/nucleotide-binding oligomerization domain-mediated NF-kappa B signaling. J. Immunol. 2010, 184, 5287-5297. [CrossRef] 
72. Queen, J.; Agarwal, S.; Dolores, J.S.; Stehlik, C.; Satchell, K.J. Mechanisms of inflammasome activation by Vibrio cholerae secreted toxins vary with strain biotype. Infect. Immun. 2015, 83, 2496-2506. [CrossRef] [PubMed]

73. Lin, W.; Fullner, K.J.; Clayton, R.; Sexton, J.A.; Rogers, M.B.; Calia, K.E.; Calderwood, S.B.; Fraser, C.; Mekalanos, J.J. Identification of a Vibrio cholerae RTX toxin gene cluster that is tightly linked to the cholera toxin prophage. Proc. Natl. Acad. Sci. USA 1999, 96, 1071-1076. [CrossRef] [PubMed]

74. Fullner, K.J.; Mekalanos, J.J. In vivo covalent cross-linking of cellular actin by the Vibrio cholerae RTX toxin. EMBO J. 2000, 19, 5315-5323. [CrossRef] [PubMed]

75. Sheahan, K.L.; Satchell, K.J. Inactivation of small Rho GTPases by the multifunctional RTX toxin from Vibrio cholerae. Cell Microbiol. 2007, 9, 1324-1335. [CrossRef] [PubMed]

76. Cordero, C.L.; Kudryashov, D.S.; Reisler, E.; Satchell, K.J. The Actin cross-linking domain of the Vibrio cholerae RTX toxin directly catalyzes the covalent cross-linking of actin. J. Biol. Chem. 2006, 281, 32366-32374. [CrossRef] [PubMed]

77. Satchell, K.J. MARTX, multifunctional autoprocessing repeats-in-toxin toxins. Infect. Immun. 2007, 75, 5079-5084. [CrossRef]

78. Satchell, K.J.F. Multifunctional-autoprocessing repeats-in-toxin (MARTX) Toxins of Vibrios. Microbiol. Spectr. 2015, 3. [CrossRef]

79. Sheahan, K.L.; Cordero, C.L.; Satchell, K.J. Autoprocessing of the Vibrio cholerae RTX toxin by the cysteine protease domain. EMBO J. 2007, 26, 2552-2561. [CrossRef]

80. Kim, B.S. The Modes of Action of MARTX Toxin Effector Domains. Toxins 2018, 10, 507. [CrossRef]

81. Fullner, K.J.; Lencer, W.I.; Mekalanos, J.J. Vibrio cholerae-induced cellular responses of polarized T84 intestinal epithelial cells are dependent on production of cholera toxin and the RTX toxin. Infect. Immun. 2001, 69, 6310-6317. [CrossRef]

82. Kim, Y.R.; Lee, S.E.; Kook, H.; Yeom, J.A.; Na, H.S.; Kim, S.Y.; Chung, S.S.; Choy, H.E.; Rhee, J.H. Vibrio vulnificus RTX toxin kills host cells only after contact of the bacteria with host cells. Cell Microbiol. 2008, 10, 848-862. [CrossRef] [PubMed]

83. Li, L.; Rock, J.L.; Nelson, D.R. Identification and characterization of a repeat-in-toxin gene cluster in Vibrio anguillarum. Infect. Immun. 2008, 76, 2620-2632. [CrossRef] [PubMed]

84. Kim, B.S.; Kim, J.-H.; Choi, S.; Park, S.; Lee, E.-Y.; Koh, S.; Ryu, C.-M.; Kim, S.-Y.; Kim, M.H. MARTX Toxin-stimulated interplay between human cells and Vibrio vulnificus. mSphere 2020, 5, e00659-20. [CrossRef] [PubMed]

85. Kim, B.S.; Gavin, H.E.; Satchell, K.J. Distinct roles of the repeat-containing regions and effector domains of the Vibrio vulnificus multifunctional-autoprocessing repeats-in-toxin (MARTX) toxin. mBio 2015, 6, e00324-15. [CrossRef]

86. Dolores, J.S.; Agarwal, S.; Egerer, M.; Satchell, K.J. Vibrio cholerae MARTX toxin heterologous translocation of beta-lactamase and roles of individual effector domains on cytoskeleton dynamics. Mol. Microbiol. 2014, 95, 590-604. [CrossRef]

87. Agarwal, S.; Kim, H.; Chan, R.B.; Agarwal, S.; Williamson, R.; Cho, W.; Paolo, G.D.; Satchell, K.J. Autophagy and endosomal trafficking inhibition by Vibrio cholerae MARTX toxin phosphatidylinositol-3-phosphate-specific phospholipase A1 activity. Nat. Commun. 2015, 6, 8745. [CrossRef]

88. Kim, B.A.; Lim, J.Y.; Rhee, J.H.; Kim, Y.R. Characterization of Prohibitin 1 as a Host Partner of Vibrio vulnificus RtxA1 Toxin. J. Infect. Dis. 2016, 213, 131-138. [CrossRef]

89. Lee, Y.; Kim, B.S.; Choi, S.; Lee, E.-Y.; Park, S.; Hwang, J.; Kwon, Y.; Hyun, J.; Lee, C.; Kim, J.F.; et al. Makes caterpillars floppy-like effector-containing MARTX toxins require host ADP-ribosylation factor (ARF) proteins for systemic pathogenicity. Proc. Natl. Acad. Sci. USA 2019, 116, 18031-18040. [CrossRef]

90. Herrera, A.; Muroski, J.; Sengupta, R.; Nguyen, H.H.; Agarwal, S.; Ogorzalek Loo, R.R.; Mattoo, S.; Loo, J.A.; Satchell, K.J.F. N-terminal autoprocessing and acetylation of multifunctional-autoprocessing repeats-in-toxins (MARTX) Makes Caterpillars Floppy-like effector is stimulated by adenosine diphosphate (ADP)-Ribosylation Factor 1 in advance of Golgi fragmentation. Cell Microbiol. 2020, 22, e13133. [CrossRef]

91. Kim, B.S.; Satchell, K.J. MARTX effector cross kingdom activation by Golgi-associated ADP-ribosylation factors. Cell Microbiol. 2016, 18, 1078-1093. [CrossRef]

92. Antic, I.; Biancucci, M.; Zhu, Y.; Gius, D.R.; Satchell, K.J. Site-specific processing of Ras and Rap1 Switch I by a MARTX toxin effector domain. Nat. Commun. 2015, 6, 7396. [CrossRef] [PubMed] 
93. Jang, S.Y.; Hwang, J.; Kim, B.S.; Lee, E.Y.; Oh, B.H.; Kim, M.H. Structural basis of inactivation of Ras and Rap1 small GTPases by Ras/Rap1-specific endopeptidase from the sepsis-causing pathogen Vibrio vulnificus. J. Biol. Chem. 2018, 293, 18110-18122. [CrossRef] [PubMed]

94. Biancucci, M.; Minasov, G.; Banerjee, A.; Herrera, A.; Woida, P.J.; Kieffer, M.B.; Bindu, L.; Abreu-Blanco, M.; Anderson, W.F.; Gaponenko, V.; et al. The bacterial Ras/Rap1 site-specific endopeptidase RRSP cleaves Ras through an atypical mechanism to disrupt Ras-ERK signaling. Sci. Signal. 2018, 11. [CrossRef]

95. Ziolo, K.J.; Jeong, H.G.; Kwak, J.S.; Yang, S.; Lavker, R.M.; Satchell, K.J. Vibrio vulnificus biotype 3 multifunctional autoprocessing RTX toxin is an adenylate cyclase toxin essential for virulence in mice. Infect. Immun. 2014, 82, 2148-2157. [CrossRef] [PubMed]

96. Belyy, A.; Raoux-Barbot, D.; Saveanu, C.; Namane, A.; Ogryzko, V.; Worpenberg, L.; David, V.; Henriot, V.; Fellous, S.; Merrifield, C.; et al. Actin activates Pseudomonas aeruginosa ExoY nucleotidyl cyclase toxin and ExoY-like effector domains from MARTX toxins. Nat. Commun. 2016, 7, 13582. [CrossRef] [PubMed]

97. Gavin, H.E.; Satchell, K.J. MARTX toxins as effector delivery platforms. Pathog. Dis. 2015, 73, ftv092. [CrossRef] [PubMed]

98. Woida, P.J.; Satchell, K.J.F. Coordinated delivery and function of bacterial MARTX toxin effectors. Mol. Microbiol. 2018, 107, 133-141. [CrossRef]

99. Woida, P.J.; Satchell, K.J.F. The Vibrio cholerae MARTX toxin silences the inflammatory response to cytoskeletal damage before inducing actin cytoskeleton collapse. Sci. Signal. 2020, 13, eaaw9447. [CrossRef]

100. Schmiel, D.H.; Miller, V.L. Bacterial phospholipases and pathogenesis. Microbes Infect. 1999, 1, $1103-1112$. [CrossRef]

101. Flores-Diaz, M.; Monturiol-Gross, L.; Naylor, C.; Alape-Giron, A.; Flieger, A. Bacterial Sphingomyelinases and Phospholipases as Virulence Factors. Microbiol. Mol. Biol. Rev. 2016, 80, 597-628. [CrossRef]

102. Diener, M.; Egleme, C.; Rummel, W. Phospholipase C-induced anion secretion and its interaction with carbachol in the rat colonic mucosa. Eur. J. Pharmacol. 1991, 200, 267-276. [CrossRef]

103. Sato, H.; Frank, D.W.; Hillard, C.J.; Feix, J.B.; Pankhaniya, R.R.; Moriyama, K.; Finck-Barbancon, V.; Buchaklian, A.; Lei, M.; Long, R.M.; et al. The mechanism of action of the Pseudomonas aeruginosa-encoded type III cytotoxin, ExoU. EMBO J. 2003, 22, 2959-2969. [CrossRef] [PubMed]

104. Testa, J.; Daniel, L.W.; Kreger, A.S. Extracellular phospholipase A2 and lysophospholipase produced by Vibrio vulnificus. Infect. Immun. 1984, 45, 458-463. [CrossRef] [PubMed]

105. Fiore, A.E.; Michalski, J.M.; Russell, R.G.; Sears, C.L.; Kaper, J.B. Cloning, characterization, and chromosomal mapping of a phospholipase (lecithinase) produced by Vibrio cholerae. Infect. Immun. 1997, 65, 3112-3117. [CrossRef] [PubMed]

106. Lee, J.H.; Ahn, S.H.; Kim, S.H.; Choi, Y.H.; Park, K.J.; Kong, I.S. Characterization of Vibrio mimicus phospholipase A (PhlA) and cytotoxicity on fish cell. Biochem. Biophys. Res. Commun. 2002, 298, 269-276. [CrossRef]

107. Zhong, Y.; Zhang, X.H.; Chen, J.; Chi, Z.; Sun, B.; Li, Y.; Austin, B. Overexpression, purification, characterization, and pathogenicity of Vibrio harveyi hemolysin VHH. Infect. Immun. 2006, 74, 6001-6005. [CrossRef]

108. Li, L.; Mou, X.; Nelson, D.R. Characterization of Plp, a phosphatidylcholine-specific phospholipase and hemolysin of Vibrio anguillarum. BMC Microbiol. 2013, 13, 271. [CrossRef]

109. Taniguchi, H.; Ohta, H.; Ogawa, M.; Mizuguchi, Y. Cloning and expression in Escherichia coli of Vibrio parahaemolyticus thermostable direct hemolysin and thermolabile hemolysin genes. J. Bacteriol. 1985, 162, 510-515. [CrossRef]

110. Taniguchi, H.; Hirano, H.; Kubomura, S.; Higashi, K.; Mizuguchi, Y. Comparison of the nucleotide sequences of the genes for the thermostable direct hemolysin and the thermolabile hemolysin from Vibrio parahaemolyticus. Microb. Pathog. 1986, 1, 425-432. [CrossRef]

111. Shinoda, S.; Matsuoka, H.; Tsuchie, T.; Miyoshi, S.; Yamamoto, S.; Taniguchi, H.; Mizuguchi, Y. Purification and characterization of a lecithin-dependent haemolysin from Escherichia coli transformed by a Vibrio parahaemolyticus gene. J. Gen. Microbiol. 1991, 137, 2705-2711. [CrossRef]

112. Wan, Y.; Liu, C.; Ma, Q. Structural analysis of a Vibrio phospholipase reveals an unusual Ser-His-chloride catalytic triad. J. Biol. Chem. 2019, 294, 11391-11401. [CrossRef] [PubMed]

113. Lee, K.K.; Raynard, R.S.; Ellis, A.E. The phospholipid composition of Atlantic salmon, Salmo solar L., erythrocyte membranes. J. Fish Biol. 1989, 35, 313-314. [CrossRef] 
114. Rock, J.L.; Nelson, D.R. Identification and characterization of a hemolysin gene cluster in Vibrio anguillarum. Infect. Immun. 2006, 74, 2777-2786. [CrossRef]

115. Williams, S.G.; Manning, P.A. Transcription of the Vibrio cholerae haemolysin gene, hlyA, and cloning of a positive regulatory locus, hlyU. Mol. Microbiol. 1991, 5, 2031-2038. [CrossRef]

116. Williams, S.G.; Attridge, S.R.; Manning, P.A. The transcriptional activator HlyU of Vibrio cholerae: Nucleotide sequence and role in virulence gene expression. Mol. Microbiol. 1993, 9, 751-760. [CrossRef] [PubMed]

117. Mou, X.; Spinard, E.J.; Driscoll, M.V.; Zhao, W.; Nelson, D.R. H-NS is a negative regulator of the two hemolysin/cytotoxin gene clusters in Vibrio anguillarum. Infect. Immun. 2013, 81, 3566-3576. [CrossRef]

118. Nishi, K.; Lee, H.J.; Park, S.Y.; Bae, S.J.; Lee, S.E.; Adams, P.D.; Rhee, J.H.; Kim, J.S. Crystal structure of the transcriptional activator HlyU from Vibrio vulnificus CMCP6. FEBS Lett. 2010, 584, 1097-1102. [CrossRef]

119. Mukherjee, D.; Datta, A.B.; Chakrabarti, P. Crystal structure of HlyU, the hemolysin gene transcription activator, from Vibrio cholerae N16961 and functional implications. Biochim. Biophys. Acta 2014, 1844, 2346-2354. [CrossRef]

120. Brennan, R.G. The winged-helix DNA-binding motif: Another helix-turn-helix takeoff. Cell 1993, 74, 773-776. [CrossRef]

121. Saha, R.P.; Chakrabarti, P. Molecular modeling and characterization of Vibrio cholerae transcription regulator HlyU. BMC Struct. Biol. 2006, 6, 24. [CrossRef]

122. Mukherjee, D.; Pal, A.; Chakravarty, D.; Chakrabarti, P. Identification of the target DNA sequence and characterization of DNA binding features of HlyU, and suggestion of a redox switch for $h l y A$ expression in the human pathogen Vibrio cholerae from in silico studies. Nucleic Acids Res. 2015, 43, 1407-1417. [CrossRef] [PubMed]

123. Shi, W.; Dong, J.; Scott, R.A.; Ksenzenko, M.Y.; Rosen, B.P. The role of arsenic-thiol interactions in metalloregulation of the ars operon. J. Biol. Chem. 1996, 271, 9291-9297. [CrossRef] [PubMed]

124. Krishnan, H.H.; Ghosh, A.; Paul, K.; Chowdhury, R. Effect of anaerobiosis on expression of virulence factors in Vibrio cholerae. Infect. Immun. 2004, 72, 3961-3967. [CrossRef] [PubMed]

125. Stoebner, J.A.; Payne, S.M. Iron-regulated hemolysin production and utilization of heme and hemoglobin by Vibrio cholerae. Infect. Immun. 1988, 56, 2891-2895. [CrossRef] [PubMed]

126. Elgaml, A.; Miyoshi, S. Role of the Histone-Like Nucleoid Structuring Protein (H-NS) in the Regulation of Virulence Factor Expression and Stress Response in Vibrio vulnificus. Biocontrol. Sci. 2015, 20, 263-274. [CrossRef] [PubMed]

127. Shao, C.P.; Lo, H.R.; Lin, J.H.; Hor, L.I. Regulation of cytotoxicity by quorum-sensing signaling in Vibrio vulnificus is mediated by SmcR, a repressor of hlyU. J. Bacteriol. 2011, 193, 2557-2565. [CrossRef]

128. Lee, H.-J.; Kim, J.-A.; Lee, M.-A.; Park, S.-J.; Lee, K.-H. Regulation of haemolysin (VvhA) production by ferric uptake regulator (Fur) in Vibrio vulnificus: Repression of vvhA transcription by Fur and proteolysis of VvhA by Fur-repressive exoproteases. Mol. Microbiol. 2013, 88, 813-826. [CrossRef]

129. Kim, C.M.; Chung, Y.Y.; Shin, S.H. Iron differentially regulates gene expression and extracellular secretion of Vibrio vulnificus cytolysin-hemolysin. J. Infect. Dis. 2009, 200, 582-589. [CrossRef]

130. Browning, D.F.; Busby, S.J.W. Local and global regulation of transcription initiation in bacteria. Nat. Rev. Microbiol. 2016, 14, 638. [CrossRef]

131. Boardman, B.K.; Satchell, K.J. Vibrio cholerae strains with mutations in an atypical type I secretion system accumulate RTX toxin intracellularly. J. Bacteriol. 2004, 186, 8137-8143. [CrossRef]

132. Lee, B.C.; Lee, J.H.; Kim, M.W.; Kim, B.S.; Oh, M.H.; Kim, K.S.; Kim, T.S.; Choi, S.H. Vibrio vulnificus rtxE is important for virulence, and its expression is induced by exposure to host cells. Infect. Immun. 2008, 76, 1509-1517. [CrossRef] [PubMed]

133. Sanchez-Vazquez, P.; Dewey, C.N.; Kitten, N.; Ross, W.; Gourse, R.L. Genome-wide effects on Escherichia coli transcription from ppGpp binding to its two sites on RNA polymerase. Proc. Natl. Acad. Sci. USA 2019, 116, 8310-8319. [CrossRef] [PubMed]

134. Kim, Y.R.; Lee, S.E.; Kim, C.M.; Kim, S.Y.; Shin, E.K.; Shin, D.H.; Chung, S.S.; Choy, H.E.; Progulske-Fox, A.; Hillman, J.D.; et al. Characterization and pathogenic significance of Vibrio vulnificus antigens preferentially expressed in septicemic patients. Infect. Immun. 2003, 71, 5461-5471. [CrossRef] [PubMed]

135. Papenfort, K.; Forstner, K.U.; Cong, J.P.; Sharma, C.M.; Bassler, B.L. Differential RNA-seq of Vibrio cholerae identifies the VqmR small RNA as a regulator of biofilm formation. Proc. Natl. Acad. Sci. USA 2015, 112, E766-E775. [CrossRef] 
136. Herzog, R.; Peschek, N.; Frohlich, K.S.; Schumacher, K.; Papenfort, K. Three autoinducer molecules act in concert to control virulence gene expression in Vibrio cholerae. Nucleic Acids Res. 2019, 47, 3171-3183. [CrossRef]

137. Lee, Z.W.; Hwang, S.H.; Choi, G.; Jang, K.K.; Lee, T.H.; Chung, K.M.; Kim, B.S.; Choi, S.H. A MARTX toxin $r t x A$ gene is controlled by host environmental signals through a CRP-coordinated regulatory network in Vibrio vulnificus. mBio 2020, 11, e00723-20. [CrossRef]

138. Manneh-Roussel, J.; Haycocks, J.R.J.; Magan, A.; Perez-Soto, N.; Voelz, K.; Camilli, A.; Krachler, A.M.; Grainger, D.C. cAMP Receptor Protein Controls Vibrio cholerae Gene Expression in Response to Host Colonization. mBio 2018, 9, e00966-18. [CrossRef]

139. Fang, F.C. Antimicrobial reactive oxygen and nitrogen species: Concepts and controversies. Nat. Rev. Microbiol. 2004, 2, 820-832. [CrossRef]

140. Giel, J.L.; Nesbit, A.D.; Mettert, E.L.; Fleischhacker, A.S.; Wanta, B.T.; Kiley, P.J. Regulation of iron-sulphur cluster homeostasis through transcriptional control of the Isc pathway by [2Fe-2S]-IscR in Escherichia coli. Mol. Microbiol. 2013, 87, 478-492. [CrossRef]

141. Roope, L.S.J.; Smith, R.D.; Pouwels, K.B.; Buchanan, J.; Abel, L.; Eibich, P.; Butler, C.C.; Tan, P.S.; Walker, A.S.; Robotham, J.V.; et al. The challenge of antimicrobial resistance: What economics can contribute. Science 2019, 364, eaau4679. [CrossRef]

142. Romero, J.; Feijoo, C.G.; Navarrete, P. Antibiotics in Aquaculture-Use, Abuse and Alternatives. In Health and Environment in Aquaculture; Carvalho, E.D., David, G.S., Silva, R.J., Eds.; INTECH Open Access Publisher: London, UK, 2012. [CrossRef]

143. Baker-Austin, C. Antimicrobial Resistance in Vibrio Species. In Antimicrobial Resistance and Food Safety; Chen, C.-Y., Yan, X., Jackson, C.R., Eds.; Academic Press: San Diego, CA, USA, 2015; Chapter 6; pp. 105-118. [CrossRef]

144. Clatworthy, A.E.; Pierson, E.; Hung, D.T. Targeting virulence: A new paradigm for antimicrobial therapy. Nat. Chem. Biol. 2007, 3, 541-548. [CrossRef] [PubMed]

145. Rasko, D.A.; Sperandio, V. Anti-virulence strategies to combat bacteria-mediated disease. Nat. Rev. Drug Discov. 2010, 9, 117-128. [CrossRef] [PubMed]

146. Getz, L.J.; Thomas, N.A. The Transcriptional Regulator HlyU Positively Regulates Expression of exs $A$, Leading to Type III Secretion System 1 Activation in Vibrio parahaemolyticus. J. Bacteriol. 2018, 200. [CrossRef] [PubMed]

147. Imdad, S.; Chaurasia, A.K.; Kim, K.K. Identification and Validation of an Antivirulence Agent Targeting HlyU-Regulated Virulence in Vibrio vulnificus. Front. Cell. Infect. Microbiol. 2018, 8. [CrossRef]

148. Imdad, S.; Batool, N.; Pradhan, S.; Chaurasia, A.; Kim, K. Identification of 2', 4' -Dihydroxychalcone as an Antivirulence Agent Targeting HlyU, a Master Virulence Regulator in Vibrio vulnificus. Molecules 2018, 23, 1492. [CrossRef]

149. Lee, Z.-W.; Kim, B.S.; Jang, K.K.; Bang, Y.-J.; Kim, S.; Ha, N.-C.; Jung, Y.H.; Lee, H.J.; Han, H.J.; Kim, J.-S.; et al. Small-molecule inhibitor of HlyU attenuates virulence of Vibrio species. Sci. Rep. 2019, 9, 4346. [CrossRef]

150. Ng, W.L.; Perez, L.; Cong, J.; Semmelhack, M.F.; Bassler, B.L. Broad spectrum pro-quorum-sensing molecules as inhibitors of virulence in vibrios. PLoS Pathog. 2012, 8, e1002767. [CrossRef]

151. Kim, B.S.; Jang, S.Y.; Bang, Y.J.; Hwang, J.; Koo, Y.; Jang, K.K.; Lim, D.; Kim, M.H.; Choi, S.H. QStatin, a Selective Inhibitor of Quorum Sensing in Vibrio Species. mBio 2018, 9, e02262-17. [CrossRef]

(C) 2020 by the author. Licensee MDPI, Basel, Switzerland. This article is an open access article distributed under the terms and conditions of the Creative Commons Attribution (CC BY) license (http://creativecommons.org/licenses/by/4.0/). 